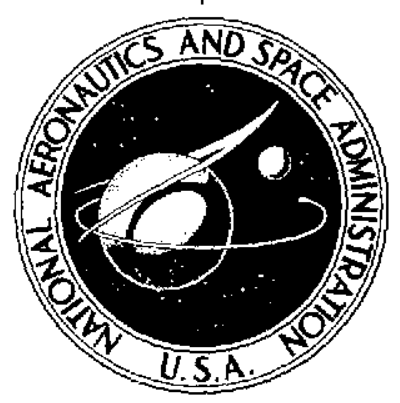

NASA TN D-7774

E
$\vdots$
$\Xi$
$\vdots$
$\vdots$

(NASA-TN-D-7774) NUMERICAL EVALUATION OF TEE SURFACE DEFORMATION OF ELASTIC SOLIDS SUBJECTED TO A HERTZIAN CONTACT STRESS (NASA) 36 P HC $\$ 3.25$

\title{
NUMERICAL EVALUATION OF
}

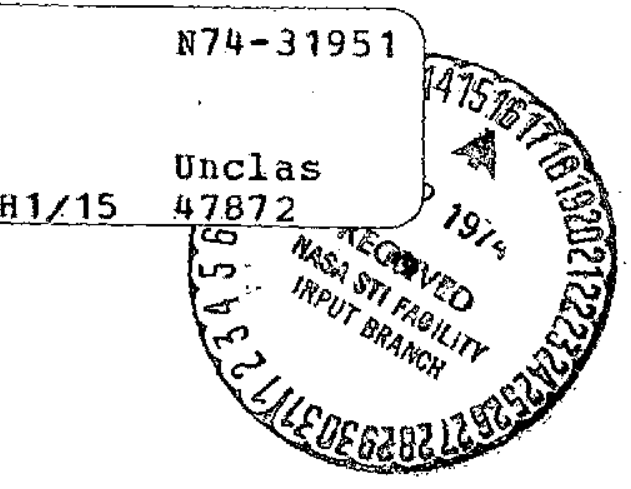

THE SURFACE DEFORMATION OF

ELASTIC SOLIDS SUBJECTED TO

A HERTZIAN CONTACT STRESS

by Bernard J. Hamrock and Duncan Dowson

Lewis Research Center

Cleveland, Obio 44135

NATIONAL aERONAUTICS AND SPACE ADMINISTRATION - WASHINGTON, D. C. - AUGUST 1974 


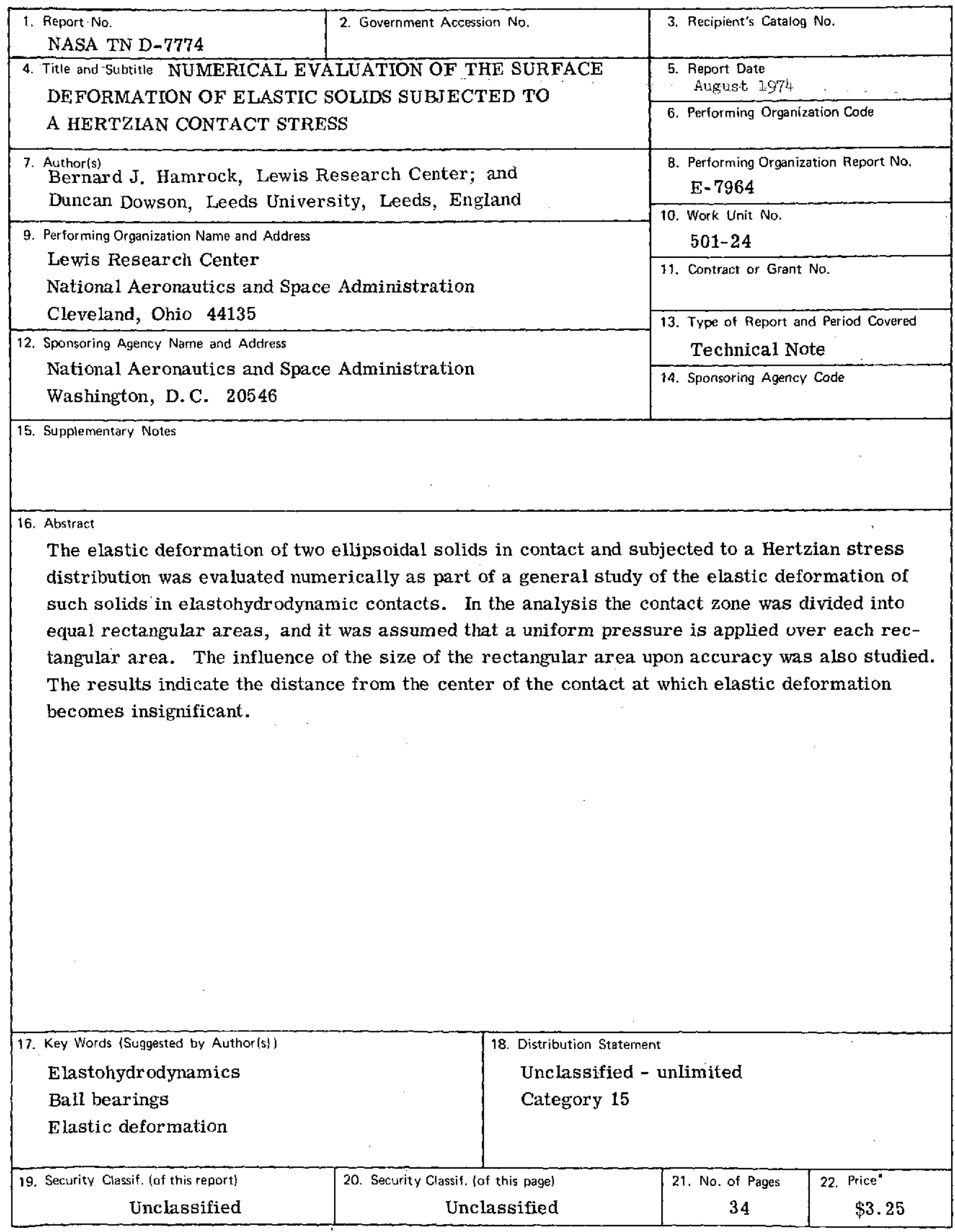

*For sale by the National Technical Information Service, Springfield, Virginia 22151 


\title{
NUMERICAL EVALUATION OF THE SURFACE DEFORMATION OF ELASTIC
}

\author{
SOLIDS SUBJECTED TO A HERTZIAN CONTACT STRESS \\ by Bernard J. Hamrock and Duncan Dowson ${ }^{*}$ \\ Lewis Research Center
}

\author{
SUMMARY
}

The elastic deformation of two ellipsoidal solids in contact and subjected to a Hertzian stress distribution was evaluated numerically as part of a general study of the elastic deformation of such solids in elastohydrodynamic contacts. In the analysis the contact zone was divided into equal rectangular areas, and it was assumed that a uniform pressure is applied over each rectangular area. The influence of the size of the rectangular area upon accuracy was also studied. The results indicate the distance from the center of the contact at which elastic deformation becomes insignificant.

\section{INTRODUCTION}

Elastohydrodynamics (ref. 1) is defined as the study of situations in which elastic deformation of the surrounding solids plays a significant role in the hydrodynamic lubrication process. This report is not concerned with the hydrodynamic lubrication process, but only with deformation due to the pressure of one elastic solid upon another.

Reference 1 distinguishes between two modes of deformation which may exist in machine elements. In one mode, the contact geometry may be affected by overall distortion of the elastic machine element resulting from applied loads, as shown in figure 1(a). In the other, the normal stress distribution in the vicinity of the contact zone may produce local elastic deformations which are significant when compared with the lubricant film thickness, as shown in figure 1(b). This is the mode of deformation with which this report concerns itself. The important distinction is that the first form of deformation is relatively insensitive to the distribution and magnitude of the stresses in the contact zone, whereas the second mode of deformation is intimately linked to the local stress conditions.

* Professor of Mechanical Engineering, Leeds University, Leeds, England. 
Before the deformation can be evaluated, the geometry of the contacting elastic solids and the semimajor and semiminor axes of the contact ellipse must be defined. The analysis is developed in general form since it will ultimately form the basis for calculations of surface deformation in elastohydrodynamic point contacts. But in order to evaluate the influence of mesh or block size upon accuracy, the numerical investigation considers only Hertzian contact stress distributions.

The deformation analysis itself assumed that the contact zone can be divided into rectangular areas and that the pressure is uniform within each rectangular area. Once the elastic deformation had been formulated, investigations were performed to answer the following queries:

(1) How fine do the semimajor and semiminor axes need to be divided to achieve a given accuracy in deformation prediction?

(2) How far from the center of the contact does deformation become insignificant compared with the separation of solids?

These questions were investigated for both light and heavy applied loads and for both equal spheres in contact and a contact that is common to the outer race of a ball bearing.

\section{SYMBOLS}

a semimajor axis of contact ellipse

$\overline{\mathrm{a}} \quad \mathrm{a} / 2 \mathrm{~m}$

b semiminor axis of contact ellipse

$\overline{\mathrm{b}} \quad \mathrm{b} / 2 \mathrm{~m}$

D defined by eq. (15)

E modulus of elasticity

$\mathrm{E}^{\prime} \quad 2 /\left(\frac{1-\nu_{\mathrm{A}}^{2}}{\mathrm{E}_{\mathrm{A}}}+\frac{1-\nu_{\mathrm{B}}^{2}}{\mathrm{E}_{\mathrm{B}}}\right)$

6 elliptical integral of second kind

F normal applied load

$F$ elliptical integral of first kind

h total film thickness

$h_{0} \quad$ central film thickness due to elastohydrodynamic lubrication

$\mathrm{J}$ function of $\mathrm{k}$ defined by eq. (6)

k elliptical eccentricity parameter, $a / b$ 
$\mathbf{m}$

P dimensionless pressure, $p / E^{\prime}$

p pressure

$\mathrm{R}$ effective radius

$R_{1} \quad \mathrm{~S} / \overline{\mathrm{S}}$

$\mathrm{R}_{2} \quad \mathrm{w} / \mathrm{S}$

$\mathrm{R}_{3}$

$\overrightarrow{\mathbf{r}}$

S

$\mathrm{S}$

W

w

$\overline{\mathrm{W}}$

$\mathrm{X}, \overline{\mathrm{X}}, \mathrm{x}$

$\mathrm{Y}, \overline{\mathrm{Y}}, \mathrm{y}\}$

$\mathrm{Z}, \overline{\mathrm{Z}}, \mathrm{z}$

$\Gamma$

$\nu$

$\varphi$

Subscripts :

A

B

$\mathrm{x}, \mathrm{y}$

solid A

solid B

coordinate system defined in report

\section{GEOMETRY OF CONTACTING ELASTIC SOLIDS}

Two solids having different radii of curvature in a pair of principal planes ( $x$ and $y$ ) passing through the contact between the solids make contact at a single point under the condition of no applied load. Such a condition is called point contact and is shown in figure 2. (In fig. 2 the radius of curvature is denoted by r.) In the analysis which follows 
it was assumed that for convex surfaces as shown in figure 2 the curvature is positive but that for concave surfaces the curvature is negative.

The curvature sum and difference are defined as

$$
\begin{gathered}
\frac{1}{R}=\frac{1}{R_{x}}+\frac{1}{R_{y}} \\
\Gamma=R\left(\frac{1}{R_{x}}-\frac{1}{R_{y}}\right)
\end{gathered}
$$

where

$$
\begin{aligned}
& \frac{1}{R_{x}}=\frac{1}{r_{A x}}+\frac{1}{r_{B x}} \\
& \frac{1}{R_{y}}=\frac{1}{r_{A y}}+\frac{1}{r_{B y}}
\end{aligned}
$$

When a normal load is applied to the two solids in figure 2, the point expands to an ellipse with $a$ as the semimajor axis and $b$ as the semiminor axis. The normal applied load $F$ in figure 2 lies along the axis which passes through the center of the solids and through the point of contact and is perpendicular to a plane which is tangential to both solids at the point of contact. For the special case where $r_{\mathrm{Ay}}=r_{\mathrm{Ax}}$ and $\mathrm{r}_{\mathrm{Bx}}=$ $\mathrm{r}_{\mathrm{By}}$, the resulting contact is a circle rather than an ellipse.

The elliptical eccentricity parameter $\mathbf{k}$ is defined as

$$
\mathrm{k}=\frac{\mathrm{a}}{\mathrm{b}}
$$

From reference 2 the eccentricity parameter $\mathrm{k}$ can be written to relate the curvature difference and the elliptic integrals of the first and second kind as

$$
J(k)=\sqrt{\frac{2 \mathscr{I}-\mathscr{E}(1+\Gamma)}{\mathscr{E}(1-\Gamma)}}
$$


where

$$
\begin{aligned}
\mathscr{F} & =\int_{0}^{\pi / 2}\left[1-\left(1-\frac{1}{\mathrm{k}}\right) \sin ^{2} \varphi\right]^{-1 / 2} \mathrm{~d} \varphi \\
& =\int_{0}^{\pi / 2}\left[1-\left(1-\frac{1}{\mathrm{k}^{2}}\right) \sin ^{2} \varphi\right]^{1 / 2} \mathrm{~d} \varphi
\end{aligned}
$$

A one-point iteration method, which has been used successfully in the past (ref. 3) was used, where

$$
\mathrm{k}_{\mathrm{n}+1}=\mathrm{J}\left(\mathrm{k}_{\mathrm{n}}\right)
$$

When the elliptical eccentricity parameter $k$ is known, the semimajor and semiminor axes of the contact ellipse can be written as

$$
\begin{gathered}
a=\left(\frac{6 \mathrm{k}^{2} \mathscr{E W R R} \mathrm{x}_{\mathrm{y}}}{\pi}\right)^{1 / 3} \\
\mathrm{~b}=\frac{\mathrm{a}}{\mathrm{k}}
\end{gathered}
$$

where $\mathrm{W}$ is the load parameter and is defined as

$$
\begin{gathered}
W=\frac{F}{E^{\prime} R_{x R_{y}}} \\
E^{\prime}=\frac{2}{\left[\frac{1-\nu_{A}^{2}}{E_{A}}+\frac{1-\nu_{B}^{2}}{E_{B}}\right]}
\end{gathered}
$$


and

F normal applied load

$\nu \quad$ Poisson's ratio

E modulus of elasticity

\section{ELASTIC DEFORMATION}

In the previous section the general geometry of two ellipsoidal solids in elastic contact was summarized. In the subsequent analysis it will be convenient to consider the deformation of an equivalent elastic half-space subjected to a Hertzian pressure distribution over the ellipse of semimajor and semiminor axes, a and $b$, as previously defined. The resulting elastic deformation can be considered to be equivalent to the total deformation of two elastic ellipsoids having elastic constants $\mathrm{E}_{\mathrm{A}}, \nu_{\mathrm{A}}$ and $\mathrm{E}_{\mathrm{B}}, \nu_{\mathrm{B}}$, respectively, if the half-space is allocated the equivalent elastic parameter $E^{\prime}$ defined by equation (13).

Once the semimajor and semiminor axes of the contact ellipse have been defined, the elastic deformation which occurs inside and outside the contact zone can be evaluated. Figure 3 shows a rectangular area of uniform pressure with the coordinate system to be used. From Timoshenko and Goodier (ref. 4) the elastic deformation at a point (X, Y) of a semi-infinite solid subjected to a pressure $p$ at the point $\left(X_{1}, Y_{1}\right)$ can be written as

$$
d \bar{w}=\frac{2 p d X_{1} d Y_{1}}{\pi E^{\prime} \bar{r}}
$$

The elastic deformation at a point $(X, Y)$ due to the uniform pressure over the rectangular area $2 \overline{\mathrm{a}} \times 2 \overline{\mathrm{b}}$ is thus

$$
\bar{w}=\frac{2 P}{\pi} \int_{-\bar{a}}^{\bar{a}} \frac{d x_{1} d Y_{1}}{\sqrt{b} \frac{b}{\left(Y-Y_{1}\right)^{2}+\left(X-X_{1}\right)^{2}}}
$$

where

$$
P=\frac{p}{E^{\prime}}
$$


Integrating the preceding equation gives

$$
\overline{\mathrm{w}}=\frac{2}{\pi} \mathrm{PD}
$$

where

$$
\begin{array}{r}
D=(X+\bar{b}) \ln \left[\begin{array}{r}
(Y+\bar{a})+\sqrt{(Y+\bar{a})^{2}+(X+\bar{b})^{2}} \\
(Y-\bar{a})+\sqrt{(Y-\bar{a})^{2}+(X+\bar{b})^{2}}
\end{array}\right]+(Y+\bar{a}) \ln \cdot\left[\frac{(X+\bar{b})+\sqrt{(Y+\bar{a})^{2}+(X+\bar{b})^{2}}}{(X-\bar{b})+\sqrt{(Y+\bar{a})^{2}+(X-\bar{b})^{2}}}\right] \\
+(X-\bar{b}) \ln \left[\frac{(Y-\bar{a})+\sqrt{(Y-\bar{a})^{2}+(X-\bar{b})^{2}}}{[Y+\bar{a})+\sqrt{(Y+\bar{a})^{2}+(X-\bar{b})^{2}}}\right] \\
+(Y-\bar{a}) \ln \left[\begin{array}{l}
(X-\bar{b})+\sqrt{(Y-\bar{a})^{2}+(X-\bar{b})^{2}} \\
(X+\bar{b})+\sqrt{(Y-\bar{a})^{2}+(X+\bar{b})^{2}}
\end{array}\right.
\end{array}
$$

As a check on the validity of equation (14) the following two cases were evaluated:

Case 1: For $\overline{\mathrm{b}}=\overline{\mathrm{a}}$ and $\mathrm{X}=\mathrm{Y}=0$, equation (14) reduces to

$$
\overline{\mathrm{w}}=\frac{16}{\pi} \mathrm{pa} \ln (1+\sqrt{2})
$$

Equation (16) represents the elastic deformation at the center of a square of uniform pressure. This equation is in agreement with that shown by Timoshenko and Goodier (ref. 4, eq. (210), p. 370).

Case 2: For $\bar{b}=\bar{a}$ and $X=Y=\bar{a}$, equation (14) reduces to

$$
\overline{\mathrm{w}}=\frac{8}{\pi} \mathrm{p} \overline{\mathrm{a}} \ln (1+\sqrt{2})
$$

Equation (17) represents the elastic deformation at the corner of a square of uniform pressure. This equation is also in agreement with that in reference 4 . From equations (16) and (17) we find the corner deformation to be one-half the deformation at the center of a square block of pressure. 
Now $\bar{W}$ in equation (14) represents the elastic deformation at a point $(\mathrm{X}, \mathrm{Y})$ due to a rectangular area $2 \overline{\mathrm{a}} \times 2 \overline{\mathrm{b}}$ of uniform pressure $\mathrm{p}$. If the contact ellipse is divided into a number of equal rectangular areas, the total deformation at a point $(X, Y)$ due to the contributions of the various rectangular areas of uniform pressure in the contact ellipse can be evaluated numerically. Figure 4 shows how the area inside and outside the contact ellipse may be divided into a number of equal rectangular areas. For purposes of illustration the contact was divided into a grid of $6 \times 6$ rectangular areas. The effects of the fineness of this grid are discussed in the section COMPUTER PROGRAM. Figure 4 can be used to write the total elastic deformation at any point inside or outside the contact ellipse, caused by the rectangular areas of uniform pressure within the contact ellipse, as

$$
w_{k, l}=\frac{2}{\pi} \sum_{j=1,2, \ldots i=1,2, \ldots}^{6} \sum_{i, j}^{6} p_{m, n}
$$

where

$$
\begin{aligned}
& \mathrm{m}=|\mathrm{k}-\mathrm{i}|+1 \\
& \mathrm{n}=|l-\mathrm{j}|+1
\end{aligned}
$$

Note that $D_{1,1}$ would be $D$ in equation (15) evaluated at $X=0, Y=0$, while $D_{2}, 3$ would be evaluated at $X=\bar{b}, Y=2 \bar{a}$.

We assumed the pressure within the contact ellipse to be Hertzian. Therefore, for the coordinate system of figure 4 the dimensionless pressure is

$$
P=\frac{3 W R_{x} R}{2 \pi a b} \sqrt{1-\left(\frac{\bar{Y}-a}{a}\right)^{2}-\left(\frac{\bar{X}-b}{b}\right)^{2}}
$$

The pressure outside the contact was assumed to be zero. Therefore, for example, from figure $4, \mathbf{P}_{3,4}$ would be equivalent to the dimensionless pressure $P$ from equation (21) evaluated at $X=5 \bar{b}$ and $Y=\overline{7}$.

Equation (22) points out more explicitly the meaning of equation (18). The elastic deformation at the center of the rectangular area $w_{9,5}$ (shown in fig. 4) caused by the pressure of the various rectangular areas in the contact ellipse can be written as 


$$
\begin{gathered}
w_{9,5}=\frac{2}{\pi}\left\{\mathbf{P}_{1,1} \mathrm{D}_{9,5}+\mathbf{P}_{2,1} \mathrm{D}_{8,5}+\cdots+\mathbf{P}_{6,1} \mathrm{D}_{4,5}\right. \\
+\mathbf{P}_{1,2} \mathrm{D}_{9,4}+\mathrm{P}_{2,2} \mathrm{D}_{8,4}+\cdots+\mathrm{P}_{6,2} \mathrm{D}_{4,4} \\
\cdot \\
\cdot \\
\left.+\mathbf{P}_{1,6} \mathrm{D}_{9,2}+\mathrm{P}_{2,6} \mathrm{D}_{8,2}+\cdots+\mathrm{P}_{6,6} \mathrm{D}_{4,2}\right\}
\end{gathered}
$$

\section{FILM THICKNESS}

The distance separating the two undistorted solids shown in figure 2, for the coordinate system developed in figure 4 , can be written as

$$
\bar{S}=R_{x}-\sqrt{R_{x}^{2}-(\bar{X}-b)^{2}}+R_{y}-\sqrt{R_{y}^{2}-(\bar{Y}-a)^{2}}
$$

It has been found in reference 5 and elsewhere that the distance described in equation (23) can be approximated by

$$
S=\frac{(\bar{X}-b)^{2}}{2 R_{X}}+\frac{(\bar{Y}-a)^{2}}{2 R_{y}}
$$

The degree to which equation (24) represents the distance expressed in equation (23) is determined by the ratio

$$
\mathrm{R}_{1}=\frac{\mathrm{S}}{\overline{\mathrm{S}}}
$$

The total film thickness when a contact zone is elastohydrodynamically lubricated can be written as

$$
\mathrm{h}=\mathrm{h}_{\mathrm{o}}+\mathrm{S}(\overline{\mathrm{X}}, \overline{\mathrm{Y}})+\mathrm{w}(\overline{\mathrm{X}}, \overline{\mathrm{Y}})
$$


where

$h_{0}$ central film thickness due to elastohydrodynamic lubrication

$\mathrm{S} \quad$ film thickness due to geometry of contacting solids

w elastic deformation inside and outside contact region

The significance of the elastic deformation relative to the film thickness due to the geometry of the contacting solids can be expressed as

$$
\mathrm{R}_{2}=\frac{\mathrm{w}}{\mathrm{S}}
$$

\section{COMPUTER PROGRAM}

Figure 4 shows that we need to be concerned with the following questions:

(1) How fine must the divisions of $a$ and $b$ be? We assume that the number of divisions of $a$ and $b$ will be the same. Therefore, we can define the number of divisions as

$$
\mathrm{m}=\frac{\mathrm{a}}{2 \overline{\mathrm{a}}}=\frac{\mathrm{b}}{2 \overline{\mathrm{b}}}
$$

In this report we let $\mathrm{m}=3,4$, and 5 .

(2) How far from the semimajor and semiminor axes does $R_{2}$ (eq. (27)) become insignificant? In this study $R_{2}$ was evaluated at distances from the center of the contact of four times the semimajor and semiminor axes.

In order to check the accuracy of the elastic deformation results for $\mathrm{m}=3,4$, and 5 , the number of equal divisions along the semimajor and semiminor axes was increased by three times $(m=9,12$, and 15), and then corresponding points were compared. The following equation describes the percentage accuracy of the results compared with the finest-mesh-size predictions:

$$
R_{3}=\left(\frac{w_{m}-w_{3 m}}{w_{3 m}}\right) 100
$$

The limiting conditions that were evaluated on a computer are shown in table I. It was speculated that conclusions which could be made for these limiting conditions could also be made for any intermediate conditions. The four limiting conditions shown in 
table $I$ are two extremes of applied normal load, a light load of 8.964 newtons ( $2 \mathrm{lbf}$ ) and a heavy load of 896.4 newtons $(200 \mathrm{lbf})$. The two extremes of curvature of the solids shown in table $I$ are equal spheres in contact and a ball and outer race of a ball bearing. The elliptical eccentricity parameter $(k=a / b)$ for the equal spheres in contact is 1 and for the ball and outer race it is 5 .

The equations thus far developed were programmed on the Leeds University Internal Computers Limited (ICL) model 1906A digital computer.

\section{DISCUSSION OF RESULTS}

Tables II to XIII give the characteristics of the deformed shape of the contacting solids along the semimajor and semiminor axes when the axes are divided into three, four, and five equal divisions and the dimensionless load parameter is equated to $0.2102 \times 10^{-7}, 0.5105 \times 10^{-7}, 0.2102 \times 10^{-5}$, and $0.5105 \times 10^{-5}$. Some observations can be made about these tables:

(1) Because of the coarse grid and the elliptical pressure profile, there is not much decrease in pressure in going from the innermost to the outermost point within the contact area.

(2) The agreement of $\mathrm{S}$ with $\overline{\mathrm{S}}$ is seen to be good and is borne out by the ratio of the two expressed in terms of $R_{1}$. The biggest disagreement is seen in table VII where $R_{1}=0.9870$, which means that $\bar{S}$ is in agreement with $S$ within 1.3 percent. Because of this good agreement, $S$ will be used in defining the film thickness.

(3) The ratio $R_{2}$ of the elastic deformation to the film thickness due to the geometry of the contacting solids is seen to decrease substantially with increasing distance from the center of the contact zone. Furthermore, the predictions of the distance at which the elastic deformation becomes insignificant compared with the natural separation of the solids do not change whether we have two equal spheres or a sphere and an outer race in contact.

(4) The separation due to the geometry of the contacting solids plus the elastic deformation $(S+w)$ is very close to being constant in the contact zone. The value of $S+w$ at the farthest point from the center of the contact zone and yet still in the contact zone differs the most from the other values of $\mathrm{S}+\mathrm{w}$ in the contact zone, increasing slightly.

(5) The percentage difference in surface deformation calculations for two mesh sizes differing by a factor of 3 was shown to be small. For the worst case shown in table XI, $R_{3}$ was found to be equal to 7.494 percent. That is, the surface deformation for $m=3$ differs from the film shape at corresponding points when $\mathrm{m}=9$ by 7.5 percent, which is extremely good.

(6) Comparing tables II with V, III with VI, and so forth, which amounts to changing 
the normal applied load from 8.964 newtons (2 lbf) to 896.4 newtons (200 lbf), leads to the following conclusions:

(a) $R_{2}$ does not change in the corresponding tables. That is, regardless of the normal applied load, the ratio of the elastic deformation to the natural separation of the solids is unchanged.

(b) $R_{3}$ does not change in the corresponding tables. This condition is undoubtedly because of the condition mentioned in (a).

In order to better illustrate the results shown in the tables, figures 5 to 9 are presented. In figures 5 to 7 the solid curves represent the case of equal spheres in contact, which is represented by $R_{x}=R_{y}=0.5558$ centimeter ( 0.2188 in. ); and the dashed curves represent the ball and outer race in contact, which is represented by $R_{x}=$ $1.284 \mathrm{~cm}$ (0.5055 in.), $R_{y}=15.00 \mathrm{~cm}$ (5.906 in.). Also as a result of the observation made in discussing the tables that $R_{2}$ and $R_{3}$ are not functions of the normal applied load, the results shown in figures 5 to 7 apply for any normal applied load.

Figures 5(a) and (b) show the effects of the location along the semimajor and semiminor axes, respectively, on the percentage difference in elastic deformation when $m=3$ and 9 . Here an "edge effect" can be seen, which is a rapid rise in percentage difference in the film thickness when $\mathrm{m}=3$ and for corresponding points when $\mathrm{m}=9$. This rapid rise is due to the pressure being either zero if the center of the rectangular area shown in figure 4 is outside the contact zone or of order $10^{5}$ if the center of the rectangular area is within the contact zone. However, it is speculated that in lubricated contacts, where the pressure gradients are, in general, more gradual than those encountered near the edge of a dry Hertzian contact, this edge effect is likely to be less significant. Also note that outside the contact zone the value of $R_{3}$ decreases.

Figures 6(a) and (b) show the effect of the location along the semimajor and semiminor axes, respectively, on the percentage difference in elastic deformation when $\mathrm{m}=3,4$, and 5 and the more exact elastic deformation when $\mathrm{m}=9,12$, and 15 . These figures show a large drop in $R_{3}$ from $m=4$ to $m=5$, which also brings down the edge effect considerably. There is, therefore, a good case for letting $m=5$ in any further computer evaluations.

Figures 7 (a) and (b) show the effect of the location along the semimajor and semiminor axes, respectively, on the ratio of the elastic deformation to the distance separating the two solids in contact due to the geometry of the solids. These figures show the effect that the shape of the contact zone has on the distance from the semimajor and semiminor axes at which the elastic deformation becomes insignificant. To be more specific, from the curves we see that for equal spheres in contact (represented by solid lines in the figures) $R_{2}<0.05$ corresponds to $x>2.6 \mathrm{~b}$ and $\mathrm{y}>2.6 \mathrm{a}$. Thus, the elastic deformation is less than 5 percent of the film shape due to the geometry effects at a distance from the center of the contact zone that is no less than 2.6 times the semi- 
major or semiminor axis. For the ball and outer race in contact, $R_{2}<0.05$ corresponds to $\mathrm{y}>1.9 \mathrm{a}$ and $\mathrm{x}>4.0 \mathrm{~b}$. In other words, the elastic deformation is less than 5 percent of the film shape due to geometry effects at a distance of only 1.9 times the semimajor axis and 4.0 times the semiminor axis from the center of the contact zone.

Figures 8(a) and (b) show the effect of the location along the semimajor and semiminor axes, respectively, on the separation due to the geometry of the contacting solids plus the elastic deformation when the dimensionless load parameter is $0.2107 \times 10^{-7}$, $0.5105 \times 10^{-7}, 0.2107 \times 10^{-5}$, and $0.5105 \times 10^{-5}$. These figures show the film shape to be constant within the contact zone.

Figure 9 shows the effect of the number of divisions across the ellipse axes on the computer time for running all four conditions shown in table $I$. Here we see that the computer run time quickly becomes exorbitant as $\mathrm{m}$ is increased. This is why only selected data for $R_{3}$ were obtained.

\section{CONCLUSIONS}

A numerical analysis of the surface deformation of two contacting ellipsoidal solids has been performed. The analysis assumed that the pressure in the contact zone was Hertzian. It was also assumed that the contact zone could be divided into rectangular areas with uniform pressure within each rectangular area. The resulting equations were programmed on a digital computer. Four limiting conditions were evaluated on the computer. They consist of two extremes of applied normal loads, a light load of 8.964 newtons (2 lbf) and a heavy load of 896.4 newtons (200 lbf). The two other extremes are of the curvature of the contacting solids: two equal spheres in contact, and a ball and outer race of a ball bearing. It was speculated that conclusions which could be made for the limiting conditions could also be made for any intermediate condition.

The results indicate that division of the semimajor and semiminor axes into five equal subdivisions is adequate to obtain accurate elastic deformation results. It was also found that the elastic deformation becomes insignificant compared with the normal surface separation for two equal spheres in contact at a distance from the center of 2. 6 times the semimajor axis. For a ball and outer race in contact, it was found that a similar observation applied at a distance from the center of 1.9 times the semimajor axis and 4.0 times the semiminor axis. Finally, it was found that the separation due to the geometry of the contacting solids plus the elastic deformation $(\mathrm{S}+\mathrm{w})$ was almost constant in the contact region. However, numerical values of $\mathbf{S}+\mathrm{w}$ at points near the edge of the Hertzian contact show that a slight edge effect or error may be encountered in such regions. In lubricated contacts, where the pressure gradients are, in general, 
more gradual than those encountered near the edge of a dry Hertzian contact, this effect is likely to be less significant.

Lewis Research Center,

National Aeronautics and Space Administration, Cleveland, Ohio, May 28, 1974, 501-24.

\section{REFERENCES}

1. Dowson, D. : Elastohydrodynamic Lubrication - An Introduction and a Review of Theoretical Studies. Paper R1, Inst. of Mech. Eng., May 1965.

2. Harris, Tedric A.: Rolling Bearing Analysis. John Wiley \& Sons, Inc., 1966.

3. Hamrock, B. J.; and Anderson, W. J.: Analysis of an Arched Outer-Race Ball

Bearing Considering Centrifugal Forces. J. Lub. Tech., vol. 95, no. 3, July 1973, pp. 265-276.

4. Timoshenko, Stephen; and Goodier, J. N.: Theory of Elasticity. 2nd ed., McGrawHill Book Co., Inc., 1951.

5. Dowson, D.; and Higginson, G. R.: Elastohydrodynamic Lubrication. Pergamon Press, 1966. 
TABLE I, - INPUT CONDITIONS USED FOR COMPUTER EVALUATIONS

[Effective clastic modulus, $E^{\prime}, 21.97 \mathrm{MN} / \mathrm{cm}^{2}\left\langle 3.187 \times 10^{7} \mathrm{psi}\right)$; radius of curvature for solid A, $\mathrm{r}_{\mathrm{Ax}}=\mathrm{r}_{\mathrm{Ay}}-1.111 \mathrm{~cm}(0.4375$ in. $\left.).\right]$

\begin{tabular}{|c|c|c|c|c|c|c|c|c|c|c|c|}
\hline \multirow[t]{3}{*}{ Condition } & \multirow{3}{*}{$\begin{array}{c}\text { Dimensionless } \\
\text { load param- } \\
\text { eter, } \\
\text { W }\end{array}$} & \multirow{2}{*}{\multicolumn{2}{|c|}{$\begin{array}{c}\text { Normal applied } \\
\text { force, } \\
\text { F }\end{array}$}} & \multicolumn{4}{|c|}{ Effective radius } & \multicolumn{4}{|c|}{ Radius of curvature for solid $B$} \\
\hline & & & & \multicolumn{2}{|c|}{$\mathrm{R}_{\mathrm{x}}$} & \multicolumn{2}{|c|}{$\mathrm{R}_{\mathrm{y}}$} & \multicolumn{2}{|c|}{${ }^{\mathrm{r}} \mathrm{Bx}$} & \multicolumn{2}{|c|}{$\mathbf{r}_{\mathrm{By}}$} \\
\hline & & $\mathrm{N}$ & lbf & $\mathrm{cm}$ & in. & $\mathrm{cm}$ & in. & $\mathrm{cm}$ & in. & $\mathrm{cm}$ & in. \\
\hline 1 & $0.5105 \times 10^{-7}$ & 8. 964 & 2 & 0.5558 & 0.2188 & 0.5558 & 0.2188 & 1.111 & 0.4375 & 1.111 & 0.4375 \\
\hline 2 & $.5105 \times 10^{-5}$ & 896.4 & 200 & .5558 & .2188 & .5558 & .2188 & 1.111 & .4375 & 1. 111 & .4375 \\
\hline 3 & $.2102 \times 10^{-7}$ & 8.964 & 2 & 1.284 & .5055 & 15.00 & 5.906 & -8.260 & -3.252 & -1.200 & -.4725 \\
\hline 4 & $.2102 \times 10^{-5}$ & 896.4 & 200 & 1.284 & .5055 & 15.00 & 5.906 & -8.260 & -3.252 & -1.200 & -.4725 \\
\hline
\end{tabular}

TABLE II. - CHARACTERISTICS OF FILM SHAPE ALONG SEMIMAJOR AND SEMIMINOR AXES WHEN THESE AXES ARE DIVIDED INTO THREE EQUAL DIVISIONS AND THE DIMENSIONLESS LOAD PARAMETER IS $0.5105 \times 10^{-7}$; THAT IS, CONDITION 1 OF TABLE I, OR A SPHERE IN CONTACT WITH A SPHERE

\begin{tabular}{|c|c|c|c|c|c|c|c|c|c|c|}
\hline \multicolumn{2}{|c|}{ Coordinates } & \multicolumn{2}{|c|}{ Pressure, $\mathrm{p}$} & \multirow{2}{*}{$\begin{array}{c}\text { Ratio } \\
\mathbf{R}_{1}=\frac{\mathrm{S}}{\overline{\mathrm{S}}}\end{array}$} & \multicolumn{2}{|c|}{ Elastic deformation, $w$} & \multirow{2}{*}{$\begin{array}{c}\text { Ratio } \\
\mathrm{R}_{2}=\frac{\mathrm{w}}{\mathrm{S}}\end{array}$} & \multicolumn{2}{|c|}{ Total separation, $s+w$} & \multirow{2}{*}{$\begin{array}{c}\text { Ratio } \\
\mathbf{R}_{3}\end{array}$} \\
\hline$\overline{\mathrm{X}}$ & $\overline{\mathrm{Y}}$ & $\mathrm{N} / \mathrm{cm}^{2}$ & psi & & $\mathrm{cm}$ & in. & & $\mathrm{cm}$ & in. & \\
\hline \multirow[t]{12}{*}{$7 \bar{b}$} & $7 \overrightarrow{\mathrm{a}}$ & $0.0851 \times 10^{6}$ & $0.1235 \times 10^{6}$ & 1.000 & $0.0856 \times 10^{-3}$ & $0.0337 \times 10^{-3}$ & 35.33 & $0.0881 \times 10^{-3}$ & $0.0347 \times 10^{-3}$ & 0.7910 \\
\hline & $9 \bar{a}$ & .0745 & .1080 & & .0759 & .0299 & 6.275 & .0881 & .0347 & .9363 \\
\hline & $11 \bar{a}$ & .0462 & .0670 & & .0577 & $.022^{3}$ & 1.830 & .0892 & .0351 & 1.984 \\
\hline & $13 \bar{a}$ & 0 & 0 & $y$ & .0366 & .0144 & .6021 & .0970 & .0382 & 1.787 \\
\hline & $15 \bar{a}$ & & & .9999 & .0269 & .0106 & .2720 & .1265 & .0498 & .8633 \\
\hline & $17 \overline{\mathrm{a}}$ & & & .9999 & .0216 & .0085 & .1468 & .1697 & .0668 & .4847 \\
\hline & $19 \bar{a}$ & & & .9998 & .0183 & .0072 & .0882 & .2243 & .0883 & $-\ldots$ \\
\hline & $21 \bar{a}$ & & & .9998 & .0157 & .0062 & .0572 & .2896 & .1140 & $-\ldots-1$ \\
\hline & $23 \bar{a}$ & & & .9997 & .0137 & .0054 & .0392 & .3653 & .1438 & -..... \\
\hline & $25 \bar{a}$ & & & .9996 & .0122 & .0048 & .0282 & .4511 & .1776 & ----- \\
\hline & $27 \bar{a}$ & & & .9995 & .0112 & .0044 & .0207 & .5469 & .2153 & - n- \\
\hline & $29 \overline{\mathrm{a}}$ & 1 & $\mathbf{T}$ & .9994 & .0102 & .0040 & .0158 & .6525 & .2569 & ----- \\
\hline $9 \bar{b}$ & $7 \overrightarrow{\mathbf{a}}$ & .0745 & .1080 & 1.000 & .0759 & .0299 & 6.279 & .0881 & .0347 & .9363 \\
\hline $11 \bar{b}$ & & .0462 & .0670 & 1.000 & .0704 & .0277 & 1.832 & .0892 & .0351 & 1.987 \\
\hline $13 \overline{\mathrm{b}}$ & & 0 & 0 & 1.000 & .0366 & .0144 & .6027 & .0970 & .0382 & 1. 787 \\
\hline $15 \bar{b}$ & & & & .9999 & .0269 & .0106 & .2723 & .1262 & .0497 & .8617 \\
\hline $17 \bar{b}$ & & & & .9999 & .0216 & .0085 & .1469 & .1694 & .0667 & .4849 \\
\hline $19 \overline{\mathrm{b}}$ & & & & .9998 & .0183 & .0072 & .0883 & .2240 & .0882 & $-\cdots$ \\
\hline $21 \bar{b}$ & & & & .9998 & .0157 & .0062 & $: 0572$ & .2893 & .1139 & $-\ldots \ldots$ \\
\hline $23 \overline{\mathrm{b}}$ & & & & .9997 & .0137 & .0054 & .0392 & .3650 & .1437 & $\ldots \ldots$ \\
\hline $25 \overline{\mathrm{b}}$ & & & & .9996 & .0122 & .0048 & .0280 & .4509 & .1775 & $-\ldots$ \\
\hline $27 \bar{b}$ & & & & . 9995 & .0112 & .0044 & .0207 & .5464 & .2151 & $-\ldots-$ \\
\hline $29 \overline{\mathrm{b}}$ & & 1 & 1 & .9994 & .0102 & .0040 & .0158 & 6520 & 2567 & $\ldots$ \\
\hline
\end{tabular}


TABLE III. - CHARACTERISTICS OF FILM SHAPE ALONG SEMIMAJOR AND SEMIMINOR AXES WHEN THESE AXES ARE DIVIDED INTO FOUR EQUAL DIVISIONS AND THE DIMENSIONLESS LOAD PARAMETER IS $0.5105 \times 10^{-7}$;

THAT IS, CONDITION 1 OF TABLE I, OR A SPHERE IN CONTACT WITH A SPHERE

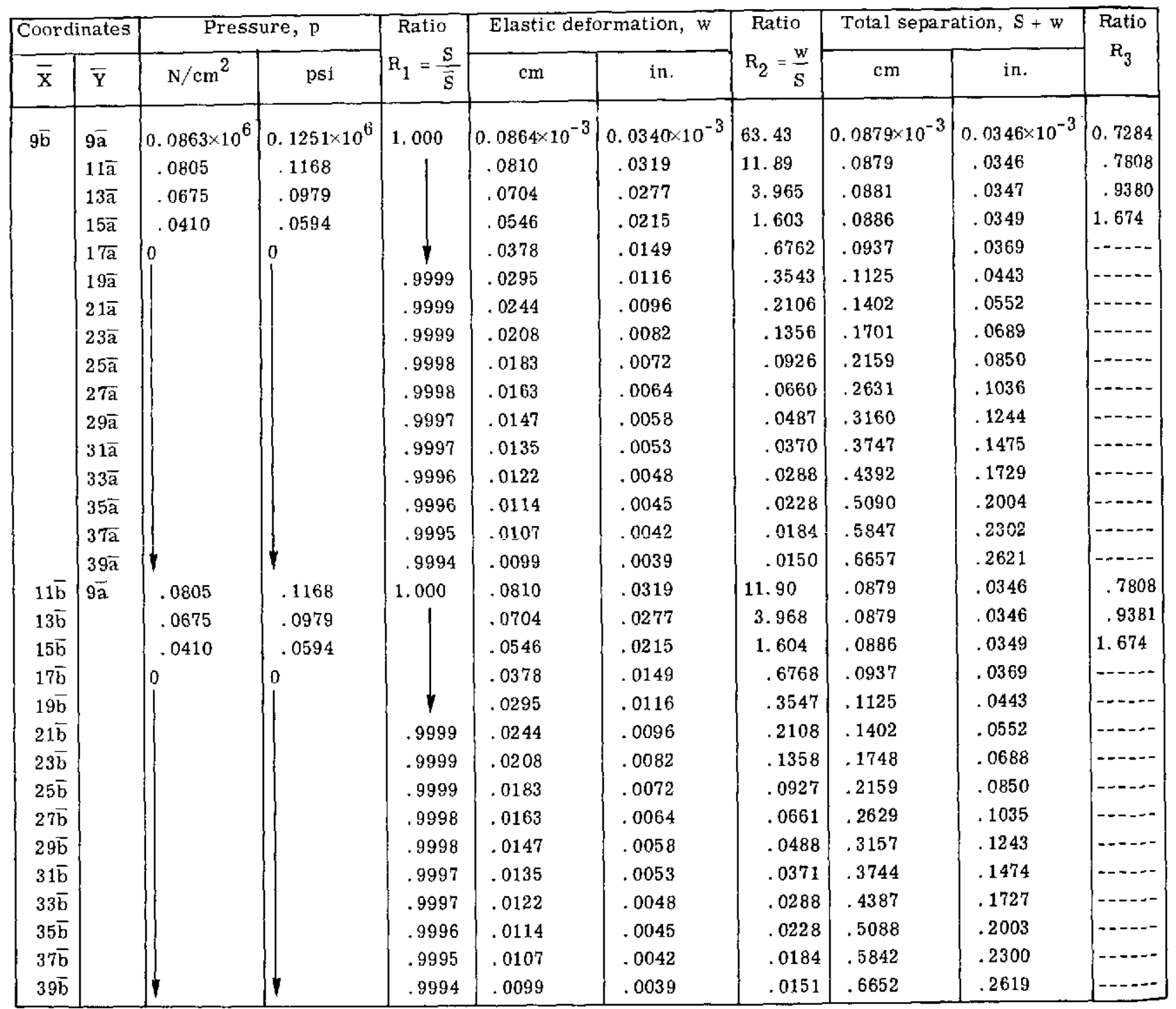


TABLE IV. - CHARACTERISTICS OF FILM SHAPE ALONG SEMIMAJOR AND SEMIMINOR AXES WHEN THESE AXES ARE DIVIDED INTO FIVE EQUAL DIVISIONS AND THE DIMENSIONLESS LOAD PARAMETER IS $0.5105 \times 10^{-7}$;

THAT IS, CONDITION 1 OF TABLE I, OR A SPHERE IN CONTACT WITH A SPHERE

\begin{tabular}{|c|c|c|c|c|c|c|c|c|c|c|}
\hline \multicolumn{2}{|c|}{ Coordinates } & \multicolumn{2}{|c|}{ Pressure, p } & \multirow{2}{*}{$\begin{array}{c}\text { Ratio } \\
R_{1}=\frac{S}{\bar{S}}\end{array}$} & \multicolumn{2}{|c|}{ Elastic deformation, w } & \multirow{2}{*}{$\begin{array}{c}\text { Ratio } \\
\mathrm{R}_{2}=\frac{\mathrm{w}}{\mathrm{S}}\end{array}$} & \multicolumn{2}{|c|}{ Total separation, $S+w$} & \multirow{2}{*}{$\begin{array}{c}\text { Ratio } \\
\mathrm{R}_{3}\end{array}$} \\
\hline $\bar{x}$ & $\bar{Y}$ & $\mathrm{~N} / \mathrm{cm}^{2}$ & psi & & $\mathrm{cm}$ & in. & & $\mathrm{cm}$ & in. & \\
\hline $11 \bar{b}$ & $11 \bar{a}$ & ก. $0867 \times 10^{6}$ & $0.1258 \times 10^{6}$ & 1.000 & $0.0864 \times 10^{-3}$ & $0.0340 \times 10^{-3}$ & 99.05 & $0.0874 \times 10^{-3}$ & $0.0344 \times 10^{-3}$ & 0.0291 \\
\hline & $13 \overline{\mathbf{a}}$ & .0832 & 1206 & & .0828 & .0326 & 19.01 & .0874 & .0344 & .0378 \\
\hline & $15 \bar{a}$ & .0754 & .1093 & & .0759 & .0299 & 6.698 & .0874 & .0344 & .0757 \\
\hline & $17 \bar{a}$ & .0620 & .0899 & & .0655 & .0258 & 3.008 & .0874 & .0344 & .1921 \\
\hline & $19 \overline{\mathbf{a}}$ & .0372 & .0539 & & .0521 & .0205 & 1.459 & .0879 & .0346 & .7276 \\
\hline & $21 \bar{a}$ & 0 & 0 & $\gamma$ & .0384 & .0151 & .7195 & .0914 & .0360 & ---- \\
\hline & $23 \bar{a}$ & & & .9999 & .0310 & .0122 & .4170 & .1052 & .0414 & ....... \\
\hline & $25 \bar{a}$ & & & & .0262 & .0103 & .2658 & .1247 & .0491 & ----- \\
\hline & $27 \bar{a}$ & & & & .0229 & .0090 & .1804 & .1444 & .0588 & $--\cdots$ \\
\hline & $29 \bar{a}$ & & & $t$ & .0203 & .0080 & .1282 & .1783 & .0702 & ----- \\
\hline & $31 \bar{a}$ & & & .9998 & .0183 & .0072 & .0944 & .2111 & .0831 &..--- \\
\hline & $33 \bar{a}$ & & & .9998 & .0165 & .0065 & .0716 & .2479 & .0976 & $-\cdots$ \\
\hline & $35 \bar{a}$ & & & .9998 & .0152 & .0060 & .0556 & .2883 & .1135 & ----- \\
\hline & $37 \bar{a}$ & & & .9997 & .0140 & .0055 & .0440 & .3325 & .1309 & $-m---4$ \\
\hline & $39 \bar{a}$ & & & .9997 & .0130 & .0051 & .0355 & .3805 & .1498 & ---- \\
\hline & $41 \bar{a}$ & & & .9996 & .0122 & .0048 & .0290 & .4321 & .1701 & -.... \\
\hline & $43 \bar{a}$ & & & .9996 & .0114 & .0045 & .0240 & .4869 & .1917 & $---\ldots$ \\
\hline & $45 \bar{a}$ & & . & .9995 & .0107 & .0042 & .0201 & .5456 & .2148 & ----- \\
\hline & $47 \sqrt{a}$ & & & .9995 & .0102 & .0040 & .0170 & .6081 & .2394 & - \\
\hline & $49 \bar{a}$ & 1 & & .9994 & .0097 & .0038 & .0145 & .6739 & .2653 & $-\cdots--$ \\
\hline $13 \bar{b}$ & $11 \bar{a}$ & .0832 & .1206 & 1.000 & .0828 & .0326 & 19.02 & .0874 & .0344 & .0408 \\
\hline $15 \bar{b}$ & & .0754 & .1093 & & .0759 & .0299 & 6.702 & .0874 & .0344 & .0757 \\
\hline $17 \overline{\mathrm{b}}$ & & .0620 & .0899 & & .0655 & .0258 & 3.010 & .0874 & .0344 & .1921 \\
\hline $19 \bar{b}$ & & .0372 & .0539 & & .0521 & .0205 & 1.460 & .0879 & .0346 & .7243 \\
\hline $21 \bar{b}$ & & 0 & 0 & $\downarrow$ & .0384 & .0151 & .7202 & .0914 & .0360 & - - - \\
\hline $23 \overline{\mathrm{b}}$ & & & & .9999 & .0310 & .0122 & .4174 & .1052 & .0414 & ------ \\
\hline $25 \overline{\mathrm{b}}$ & & & & & .0262 & .0103 & .2660 & .1247 & .0491 & ---- \\
\hline $27 \bar{b}$ & & & & & .0229 & .0090 & .1805 & .1494 & .0588 & - \\
\hline $29 \overline{\mathrm{b}}$ & & & & $\downarrow$ & .0203 & .0080 & .1283 & .1781 & .0701 & $\ldots$ \\
\hline $31 \bar{b}$ & & & & .9998 & .0183 & .0072 & .0945 & .2108 & .0830 & ---- \\
\hline $33 \bar{b}$ & & . & & .9998 & .0165 & .0065 & .0717 & .2477 & .0975 & 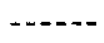 \\
\hline $35 \overline{\mathrm{b}}$ & & & & .9998 & .0152 & .0060 & .0556 & .2880 & .1134 & ----- \\
\hline $37 \bar{b}$ & & & & .9997 & .0140 & .0055 & .0441 & .3322 & .1308 & ----- \\
\hline $39 \overline{\mathrm{b}}$ & & & & .9997 & .0130 & .0051 & .0355 & .3802 & .1497 & --.-- \\
\hline $41 \overline{\mathrm{b}}$ & & & & .9996 & .0122 & .0048 & .0290 & .4315 & .1699 & ------ \\
\hline $43 \bar{b}$ & & & & .9996 & .0114 & .0045 & .0240 & .4867 & .1916 & 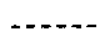 \\
\hline $45 \bar{b}$ & & & & .9995 & .0107 & .0042 & .0201 & .5453 & .2147 & $\ldots$ \\
\hline $47 \overline{\mathrm{b}}$ & & & & .9995 & .0102 & .0040 & .0170 & .6076 & .2392 & ---- \\
\hline $49 \overline{\mathrm{b}}$ & & 1 & 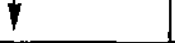 & .9994 & .0097 & .0038 & .0145 & .6734 & .2651 & ---- \\
\hline
\end{tabular}


TABLE V. - CHARAC'TERISTICS OF FILM SHAPE ALONG SEMIMAJOR AND SEMIMINOR AXES WHEN THESE AXES ARE DIVIDED INTO THREE EQUAL DIVISIONS AND THE DIMENSIONLESS LOAD PARAMETER IS $0.5105 \times 10^{-5}$;

THAT IS, CONDITION 2 OF TABLE I, OR A SPHERE IN CONTACT WITH A SPHERE

\begin{tabular}{|c|c|c|c|c|c|c|c|c|c|c|}
\hline \multicolumn{2}{|c|}{ Coordinates } & \multicolumn{2}{|c|}{ Pressure, p } & \multirow{2}{*}{$\begin{array}{c}\text { Ratio } \\
\mathrm{R}_{1}=\frac{\mathrm{S}}{\overline{\mathrm{S}}}\end{array}$} & \multicolumn{2}{|c|}{ Elastic deformation, w } & \multirow{2}{*}{$\begin{array}{c}\text { Ratio } \\
R_{2}=\frac{w}{S}\end{array}$} & \multicolumn{2}{|c|}{ Total separation, $\mathrm{S}+\mathrm{w}$} & \multirow{2}{*}{$\begin{array}{l}\text { Ratio } \\
\mathrm{R}_{3}\end{array}$} \\
\hline $\mathrm{X}$ & $\vec{Y}$ & $\mathrm{~N} / \mathrm{cm}^{2}$ & psi & & $\mathrm{cm}$ & in. & & $\mathrm{cm}$ & in. & \\
\hline \multirow[t]{12}{*}{$7 \bar{b}$} & $7 \vec{a}$ & $0.3953 \times 10^{6}$ & $0.5734 \times 10^{6}$ & 1.000 & 1. $844 \times 10^{-3}$ & $0.7261 \times 10^{-3}$ & 35.33 & $1.897 \times 10^{-3}$ & $0.7467 \times 10^{-3}$ & 0.8136 \\
\hline & $\overline{9 a}$ & .3457 & .5014 & .9998 & 1.639 & .6451 & 6.275 & 1.900 & .7479 & 1.088 \\
\hline & $11 \bar{a}$ & .2144 & .3109 & .9994 & 1.243 & .4892 & 1. 830 & 1.922 & .7565 & 3.102 \\
\hline & $13 \bar{a}$ & 0 & 0 & .9989 & .7861 & .3095 & .6021 & 2.092 & .8235 & 4.897 \\
\hline & $15 \bar{a}$ & & & .9981 & .5824 & .2293 & .2720 & 2.723 & 1. 072 & 4. 170 \\
\hline & $17 \bar{a}$ & & & .9972 & .4676 & .1841 & .1468 & 3.653 & 1. 438 & 3.924 \\
\hline & $19 \overline{\mathbf{a}}$ & & & .9960 & .3917 & .1542 & .0882 & 4.831 & 1.902 & ----- \\
\hline & $21 \bar{a}$ & & & .9947 & .3376 & .1329 & .0572 & 6.238 & 2. 456 & $-\ldots$ \\
\hline & $23 \bar{a}$ & & & .9932 & .2967 & .1168 & .0392 & 7.869 & 3.098 & ----- \\
\hline & $25 \bar{a}$ & & & .9915 & .2647 & .1042 & .0280 & 9.718 & 3,826 & $-\cdots--$ \\
\hline & $27 \bar{a}$ & & & .9896 & .2390 & .0941 & .0207 & 11.78 & 4.638 & $--n .$. \\
\hline & $29 \overline{\mathbf{a}}$ & 1 & I & .9874 & .2179 & .0858 & .0158 & 14.06 & 5.535 & $---\cdots$ \\
\hline $9 \bar{b}$ & $7 \bar{a}$ & .3457 & .5014 & .9998 & 1.639 & .6451 & 6.279 & 1.900 & .7479 & 1.086 \\
\hline $11 \bar{b}$ & & .2144 & .3109 & .9994 & 1.243 & .4893 & 1. 832 & 1.922 & .7564 & 3.104 \\
\hline $13 \overline{\mathrm{b}}$ & & 0 & 0 & .9989 & .7861 & .3096 & .6027 & 2. 092 & .8232 & 4. 896 \\
\hline $15 \bar{b}$ & & & & .9981 & .5824 & .2294 & .2723 & 2. 723 & 1.072 & 4.164 \\
\hline $17 \bar{b}$ & & & & .9972 & .4676 & .1841 & .1469 & 3.653 & 1.438 & 3.922 \\
\hline $19 \overline{\mathrm{b}}$ & & & & .9960 & .3917 & .1543 & .0883 & 4. 829 & 1.901 & $-\cdots \cdot-$ \\
\hline $21 \vec{b}$ & & & & .9947 & .3317 & .1329 & .0572 & 6.236 & 2. 455 & $-\cdots-$ \\
\hline $23 \overline{\mathrm{b}}$ & & & & .9932 & .2967 & .1168 & .0392 & 7.864 & 3.096 & ---- \\
\hline $25 \bar{b}$ & & & & .9915 & .2649 & .1043 & .0280 & 9.710 & 3.823 & $-\cdots---$ \\
\hline $27 \bar{b}$ & & & & .9896 & .2393 & .0942 & .0207 & 11.77 & 4.635 & ----- \\
\hline $29 \overline{\mathrm{b}}$ & & & & .9874 & .2182 & .0859 & .0158 & 14.05 & 5.531 & $-\ldots$ \\
\hline
\end{tabular}


TABLE VI. - CHARACTERISTICS OF FILM SHAPE ALONG SEMIMAJOR AND SEMIMINOR AXES WHEN THESE AXES ARE DIVIDED INTO FOUR EQUAL DIVISIONS AND THE DIMENSIONLESS PARAMETER IS $0.5105 \times 10^{-5}$; THAT IS, CONDITION 2 OF TABLE I, OR A SPHERE IN CONTACT WITH A SPHERE

\begin{tabular}{|c|c|c|c|c|c|c|c|c|c|c|}
\hline \multicolumn{2}{|c|}{ Coordinates } & \multicolumn{2}{|c|}{ Pressure, p } & \multirow{2}{*}{$\begin{array}{c}\text { Ratio } \\
R_{1}=\frac{S}{\bar{S}}\end{array}$} & \multicolumn{2}{|c|}{ Elastic deformation, $w$} & \multirow{2}{*}{$\begin{array}{c}\text { Ratio } \\
\mathrm{R}_{2}=\frac{\mathrm{w}}{\mathrm{S}}\end{array}$} & \multicolumn{2}{|c|}{ Total separation, $\mathrm{s}+\mathrm{w}$} & \multirow{2}{*}{$\begin{array}{c}\text { Ratio } \\
\mathrm{R}_{3}\end{array}$} \\
\hline$\overline{\mathrm{X}}$ & $\bar{Y}$ & $\mathrm{~N} / \mathrm{cm}^{2}$ & psi & & $\mathrm{cm}$ & in. & & $\mathrm{cm}$ & in. & \\
\hline \multirow[t]{16}{*}{$9 \overline{\mathrm{b}}$} & $9 \bar{a}$ & $0.4004 \times 10^{6}$ & $0.5807 \times 10^{6}$ & 1.000 & 1. $863 \times 10^{-3}$ & $0.7333 \times 10^{-3}$ & 63.43 & 1. $892 \times 10^{-3}$ & $0.7448 \times 10^{-3}$ & 0.7391 \\
\hline & $1 \mathrm{i} \bar{a}$ & .3736 & .5419 & .9999 & 1.746 & .6874 & 11.89 & 1.893 & .7452 & .8450 \\
\hline & $13 \bar{a}$ & .3134 & .4546 & .9997 & 1.514 & .5962 & 3.965 & 1. 896 & .7465 & 1.180 \\
\hline & $15 \bar{a}$ & .1902 & .2759 & .9994 & 1. 177 & .4633 & 1.603 & 1.911 & .7525 & 2.748 \\
\hline & $17 \mathrm{a}$ & 0 & 0 & .9989 & .8143 & .3206 & .6762 & 2. 019 & .7948 & $-\cdots-1$ \\
\hline & $19 \overline{\mathrm{a}}$ & & & .9984 & .6350 & .2500 & .3543 & 2.427 & .9555 & $-\ldots-n$ \\
\hline & $21 \bar{a}$ & & & .9978 & .5258 & .2070 & .2106 & 3.023 & 1.190 & 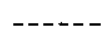 \\
\hline & $23 \bar{a}$ & & & .9970 & .4503 & .1773 & .1356 & 3.769 & 1.484 & - \\
\hline & $25 \bar{a}$ & & & .9962 & .3942 & .1552 & .0926 & 4.653 & 1. 832 & $\cdots$ \\
\hline & $27 \bar{a}$ & & & .9952 & .3510 & .1382 & .0660 & 5.669 & 2.232 & $\cdots$ \\
\hline & $29 \bar{a}$ & & & .9942 & .3165 & .1246 & .0487 & 6.810 & 2.681 & $\ldots$ \\
\hline & $31 \bar{a}$ & & & .9930 & .2883 & .1135 & .0370 & 8. 072 & 3.178 & $-\cdots$ \\
\hline & $33 \bar{a}$ & & & .9917 & .2647 & .1042 & .0288 & 9.459 & 3.724 & $\ldots$ \\
\hline & $35 \bar{a}$ & & & .9903 & .2446 & .0963 & .0228 & 10.97 & 4. 318 & ----- \\
\hline & $37 \bar{a}$ & & & .9888 & .2276 & .0896 & .0184 & 12.60 & 4.959 & $\ldots$ \\
\hline & $39 \bar{a}$ & 1 & 1 & .9872 & .2126 & .0837 & .0150 & 14.34 & 5.647 & $\cdots$ \\
\hline $11 \bar{b}$ & $9 \overrightarrow{\mathrm{a}}$ & .3736 & .5419 & .9999 & 1.746 & .6874 & 11.90 & 1.893 & .7452 & .8450 \\
\hline $13 \overline{\mathrm{b}}$ & & .3134 & .4546 & .9997 & 1.514 & .5962 & 3.968 & 1. 896 & .7464 & 1. 178 \\
\hline $15 \bar{b}$ & & .1902 & .2759 & .9994 & 1.177 & .4634 & 1.604 & 1.911 & .7523 & 2.747 \\
\hline $17 \bar{b}$ & & 0 & 0 & .9989 & .8143 & .3207 & .6768 & 2.018 & .7946 & $\ldots$ \\
\hline $19 \overline{\mathrm{b}}$ & & & & .9984 & .6350 & .2500 & .3547 & 2.426 & .9550 & $-\ldots$ \\
\hline $21 \bar{b}$ & & & & .9978 & .5258 & .2071 & .2108 & $3.02 \dot{0}$ & 1. 189 & $-\ldots$ \\
\hline $23 \bar{b}$ & & & & .9970 & .4503 & .1773 & .1358 & 3,767 & 1.483 & $-\ldots$ \\
\hline $25 \overline{\mathrm{b}}$ & & & & .9962 & .3942 & .1553 & .0927 & 4.651 & 1. 831 & $-\ldots$ \\
\hline $27 \overline{\mathrm{b}}$ & & & & .9952 & .3510 & .1382 & .0661 & 5,664 & 2.230 & $-\ldots$ \\
\hline $29 \overline{\mathrm{b}}$ & & & & .9942 & .3165 & .1246 & .0488 & 6.805 & 2.679 & 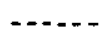 \\
\hline $31 \bar{b}$ & & & & .9930 & .2883 & .1135 & .0371 & 8.067 & 3.176 & $-\ldots$ \\
\hline $33 \bar{b}$ & & & & .9917 & .2647 & .1042 & .0288 & 9.454 & 3.722 & $-\cdots$ \\
\hline $35 \bar{b}$ & & & & .9903 & .2446 & .0963 & .0228 & 10.96 & 4. 315 & $--\cdots$ \\
\hline $37 \bar{b}$ & & & & .9888 & .2276 & .0896 & .0184 & 12.59 & 4. 955 & $-\ldots$ \\
\hline $39 \bar{b}$ & & 1 & 1 & .9872 & .2126 & .0837 & .0151 & 14.33 & 5.643 & $-\ldots$ \\
\hline
\end{tabular}


TABLE VII. - CHARACTERISTICS OF FILM SHAPE ALONG SEMIMAJOR AND SEMIMINOR AXES WHEN THESE AXES ARE DIVIDED INTO FIVE EQUAL DIVISIONS AND THE DIMENSIONLESS LOAD PARAMETER IS $0.5105 \times 10^{-5}$;

THAT IS, CONDITION 2 OF TABLE I, OR A SPHERE IN CONTACT WITH A SPHERE

\begin{tabular}{|c|c|c|c|c|c|c|c|c|c|c|}
\hline \multicolumn{2}{|c|}{ Coordinates } & \multicolumn{2}{|c|}{ Pressure, p } & \multirow{2}{*}{$\begin{array}{c}\text { Ratio } \\
\mathrm{R}_{1}=\frac{\mathrm{S}}{\overline{\mathrm{S}}}\end{array}$} & \multicolumn{2}{|c|}{ Elastic deformation, w } & \multirow{2}{*}{$\begin{array}{l}\text { Ratio } \\
\mathrm{R}_{2}=\frac{\mathrm{w}}{\mathrm{S}}\end{array}$} & \multicolumn{2}{|c|}{ Total separation, $\mathrm{S}+\mathrm{w}$} & \multirow{2}{*}{$\begin{array}{c}\text { Ratio } \\
\mathrm{R}_{3}\end{array}$} \\
\hline $\mathrm{X}$ & $\bar{Y}$ & $\mathrm{~N} / \mathrm{cm}^{2}$ & $\mathrm{psi}$ & & $\mathrm{cm}$ & in. & & $\mathrm{cm}$ & in. & \\
\hline $11 \bar{b}$ & $11 \bar{a}$ & $0.4027 \times 10^{6}$ & $0.5840 \times 10^{6}$ & 1.000 & $1.862 \times 10^{-3}$ & $0.7329 \times 10^{-3}$ & 99.05 & $1.880 \times 10^{-3}$ & $0.7403 \times 10^{-3}$ & 0.0287 \\
\hline & $13 \bar{a}$ & .3859 & .5597 & .9999 & 1.787 & .7034 & 19.01 & 1.881 & .7404 & .0398 \\
\hline & $15 \vec{a}$ & .3499 & .5075 & .9998 & $1.637^{\circ}$ & .6445 & 6.698 & 1. 881 & .7407 & .0854 \\
\hline & $17 \bar{a}$ & .2876 & .4172 & .9996 & 1.414 & .5566 & 3.008 & 1.884 & .7417 & .2558 \\
\hline & $19 \bar{a}$ & .1726 & .2503 & .9993 & 1. 124 & .4427 & 1. 459 & 1.895 & .7461 & 1.228 \\
\hline & $21 \bar{a}$ & 0 & 0 & .9990 & .8252 & .3249 & .7195 & 1.972 & .7764 & ----- \\
\hline & $23 \bar{a}$ & & & .9986 & .6662 & .2623 & .4170 & 2.264 & .8915 & $-\cdots-$ \\
\hline & $25 \bar{a}$ & & & .9981 & .5646 & .2223 & .2658 & 2.690 & 1.059 & $-\cdots$ \\
\hline & $27 \mathrm{a}$ & & & .9976 & .4917 & .1936 & .1804 & 3.218 & 1.267 & $\cdots$ \\
\hline & $29 \bar{a}$ & & & .9970 & .4361 & .1717 & .1282 & 3.840 & 1.512 & ---.- \\
\hline & $31 \bar{a}$ & & & .9963 & .3922 & .1544 & .0944 & 4.547 & 1.790 & $-\cdots$ \\
\hline & $\overline{3} \overline{3} \bar{a}$ & & & .9955 & .3566 & .1404 & .0716 & 5.339 & 2. 102 & $\ldots$ \\
\hline & $35 \bar{a}$ & & & .9947 & .3272 & .1288 & .0556 & 6.213 & 2. 446 & --- \\
\hline & $37 \bar{a}$ & & & .9938 & .3020 & .1189 & .0440 & 7.165 & 2.821 & $\cdots$ \\
\hline & $39 \bar{a}$ & & & .9928 & .2807 & .1105 & .0355 & 8.197 & 3.227 & $-\ldots$ \\
\hline . & $41 \bar{a}$ & & & .9918 & .2621 & .1032 & .0290 & 9.307 & 3.664 & $\ldots$ \\
\hline & $43 \bar{a}$ & & & .9907 & .2459 & .0968 & .0240 & 10.49 & 4.131 & $-\cdots$ \\
\hline & $45 \bar{a}$ & & & .9895 & .2316 & .0912 & .0201 & 11.76 & 4.629 & $-\cdots-$ \\
\hline & $47 \mathrm{a}$ & & & .9883 & .2189 & .0862 & .0170 & 13.10 & 5.157 & $\cdots \cdots=2-$ \\
\hline & $49 \bar{a}$ & 1 & 1 & .9870 & .2075 & .0817 & .0145 & 14.52 & 5.715 & $\cdots$ \\
\hline $13 \bar{b}$ & $11 \overline{\mathrm{a}}$ & .3859 & .5597 & 9999 & 1.787 & .7034 & 19.02 & 1.881 & .7404 & .0412 \\
\hline $15 \bar{b}$ & & .3499 & .5075 & .9998 & 1.637 & .6445 & 6.702 & 1.881 & .7407 & .0854 \\
\hline $17 \bar{b}$ & & .2876 & .4172 & .9996 & 1.414 & .5567 & 3.010 & 1.884 & .7416 & .2557 \\
\hline $19 \bar{b}$ & & .1726 & .2503 & .9993 & 1.124 & .4427 & 1.460 & 1.895 & .7460 & 1.228 \\
\hline $21 \bar{b}$ & & 0 & 0 & .9990 & .8252 & .3249 & .7202 & 1.971 & .7761 & $\ldots$ \\
\hline $23 \bar{b}$ & & & & .9986 & .6662 & .2624 & .4174 & 2.263 & .8911 & $-\cdots--$ \\
\hline $25 \overline{\mathrm{b}}$ & & & & .9981 & .5646 & .2224 & .2660 & 2.687 & 1. 058 & $\cdots$ \\
\hline $27 \bar{b}$ & & & & .9976 & .4917 & .1936 & .1805 & 3.216 & 1. 266 & ----- \\
\hline $29 \overline{\mathrm{b}}$ & & & & .9970 & .4361 & .1718 & .1283 & 3.838 & 1.511 & $-\cdots$ \\
\hline $31 \bar{b}$ & & & & .9963 & .3922 & .1545 & .0945 & 4.544 & 1.789 & $-\cdots$ \\
\hline $33 \bar{b}$ & & & & .9955 & .3566 & .1404 & .0717 & 5.337 & 2.101 & $-\cdots$ \\
\hline $35 \bar{b}$ & & & & .9947 & .3272 & 1288 & .0556 & 6.208 & 2.444 & $-\cdots$ \\
\hline $37 \overline{\mathrm{b}}$ & & & & .9938 & .3020 & .1190 & .0441 & 7.160 & 2.819 & $-\cdots$ \\
\hline $39 \vec{b}$ & & & & .9929 & .2807 & .1105 & .0355 & 8. 192 & 3.225 & $-\cdots$ \\
\hline $41 \overline{\mathrm{b}}$ & & & & .9918 & .2621 & .1032 & .0290 & 9.299 & 3.661 & $-\cdots$ \\
\hline $43 \overline{\mathrm{b}}$ & & & & .9907 & .2459 & .0969 & .0240 & 10.49 & 4.128 & $\cdots$ \\
\hline $45 \overline{\mathrm{b}}$ & & & & .9895 & .2316 & .0912 & .0201 & 11.75 & 4.625 & $\cdots$ \\
\hline $47 \overline{\mathrm{b}}$ & & & & .9883 & .2189 & .0862 & .0170 & 13.09 & 5.153 & $-\cdots$ \\
\hline $49 \overline{\mathrm{b}}$ & & 1 & 1 & .9870 & .2075 & .0817 & .0145 & 14.51 & 5.711 & $-\cdots$ \\
\hline
\end{tabular}


TABLE VIII. - CHARACTERISTICS OF FILM SHAPE ALONG SEMIMAJOR AND SEMIMINOR AXES WHEN THESE AXES ARE DIVIDED INTO THREE EQUAL DIVISIONS AND THE DIMENSIONLESS LOAD

PARAMETER IS $0.2102 \times 10^{-7}$; THAT IS, CONDITION 3 OF TABLE I, OR A SPHERE

IN CONTACT WITH AN OUTER-RACE GROOVE

[Ratio $\left.\mathrm{R}_{1}=\mathrm{S} / \overline{\mathrm{S}}, 1.000.\right]$

\begin{tabular}{|c|c|c|c|c|c|c|c|c|c|}
\hline \multicolumn{2}{|c|}{ Coordinates } & \multicolumn{2}{|c|}{ Pressure, $p$} & \multicolumn{2}{|c|}{ Elastic deformation, w } & \multirow{2}{*}{$\begin{array}{l}\text { Ratio } \\
\mathrm{R}_{2}=\frac{\mathrm{w}}{\mathrm{S}}\end{array}$} & \multicolumn{2}{|c|}{ Total separation, $S+w$} & \multirow{2}{*}{$\begin{array}{c}\text { Ratio } \\
\mathrm{R}_{3}\end{array}$} \\
\hline $\bar{x}$ & $\overline{\mathrm{Y}}$ & $\mathrm{N} / \mathrm{cm}^{2}$ & psi & $\mathrm{cm}$ & in. & & $\mathrm{cm}$ & in. & \\
\hline \multirow[t]{12}{*}{$7 \bar{b}$} & $7 \bar{a}$ & $0.0248 \times 10^{6}$ & $0.0360 \times 10^{6}$ & $0.0399 \times 10^{-3}$ & $0.0157 \times 10^{-3}$ & 35,42 & $0.0409 \times 10^{-3}$ & $0.0161 \times 10^{-3}$ & 1.030 \\
\hline & $9 \vec{a}$ & .0217 & .0315 & .0338 & .0133 & 4. 662 & .0409 & .0161 & 1. 135 \\
\hline & $11 \bar{a}$ & .0134 & .0195 & .0210 & .0087 & 1.132 & .0414 & .0163 & 4.030 \\
\hline & $13 \bar{a}$ & 0 & 0 & .0102 & .0040 & .2705 & .0480 & .0189 & 7. 494 \\
\hline & $15 \bar{a}$ & & & .0071 & .0028 & .1128 & .0691 & .0272 & 4.993 \\
\hline & $17 \bar{a}$ & & & .0056 & .0022 & .0591 & .0983 & .0387 & 4.350 \\
\hline & $19 \bar{a}$ & & & .0046 & .0018 & .0351 & .1339 & .0527 & $-\cdots-$ \\
\hline & $21 \bar{a}$ & & & .0038 & .0015 & .0225 & .1760 & .0693 & ---- \\
\hline & $23 \bar{a}$ & & & .0033 & .0013 & .0154 & .2243 & .0883 & ---- \\
\hline & $25 \bar{a}$ & & & .0030 & .0012 & .0109 & .2789 & .1098 & ---- \\
\hline & $27 \bar{a}$ & & 4 & .0028 & .0011 & .0081 & .3396 & .1337 & ---- \\
\hline & $29 \bar{a}$ & $\varphi$ & & .0025 & .0010 & .0061 & .4067 & .1601 & --- \\
\hline $9 \bar{b}$ & $7 \bar{a}$ & .0217 & .0315 & .0371 & .0146 & 9.205 & .0411 & .0162 & 1. 271 \\
\hline $11 \bar{b}$ & & .0134 & .0195 & .0315 & .0124 & 3.210 & .0414 & .0163 & 2. 283 \\
\hline $13 \dot{\mathrm{b}}$ & & 0 & 0 & .0249 & .0098 & 1.340 & .0434 & .0171 & 2. 820 \\
\hline $15 \bar{b}$ & & & & .0211 & .0083 & .6966 & .0511 & .0201 & 2.544 \\
\hline $17 \bar{b}$ & & & & .0183 & .0072 & .4114 & .0630 & .0248 & 2.517 \\
\hline $19 \bar{b}$ & & & & .0163 & .0064 & .2638 & .0782 & .0308 & ----- \\
\hline $21 \bar{b}$ & & & & .0147 & .0058 & .1794 & .0970 & .0382 & $-\cdots$ \\
\hline $23 \overline{\mathrm{b}}$ & & & & .0135 & .0053 & .1276 & .1189 & .0468 & -.... \\
\hline $25 \bar{b}$ & & & & .0124 & .0049 & .0940 & .1438 & .0566 & $\ldots$ \\
\hline $27 \bar{b}$ & & & & .0114 & .0045 & .0712 & .1720 & .0677 & $-\ldots$ \\
\hline $29 \overline{\mathrm{b}}$ & & 1 & 1 & .0107 & .0042 & .0552 & .2029 & .0799 & -- \\
\hline
\end{tabular}


TABLE IX. - CHARACTERISTICS OF FILM SHAPE ALONG SEMIMAJOR AND SEMIMINOR AXES WHEN THESE AXES ARE DIVIDED INTO FOUR EQUAL DIVISIONS AND THE DIMENSIONLESS LOAD PARAMETER IS $0.2102 \times 10^{-7}$; THAT IS, CONDITION 3 OF TABLE I, OR A SPHERE IN CONTACT WITH AN OUTER-RACE GROOVE $\left[\right.$ Ratio $\left.\mathrm{R}_{1}=\mathrm{S} / \overline{\mathrm{S}}, 1.000.\right]$

\begin{tabular}{|c|c|c|c|c|c|c|c|c|c|}
\hline \multicolumn{2}{|c|}{ Coordinates } & \multicolumn{2}{|c|}{ Pressure, $p$} & \multicolumn{2}{|c|}{ Elastic deformation, $w$} & \multirow{2}{*}{$\begin{array}{c}\text { Ratio } \\
\mathrm{R}_{2}=\frac{\mathrm{w}}{\mathrm{S}}\end{array}$} & \multicolumn{2}{|c|}{ Total separation, $S+w$} & \multirow{2}{*}{$\begin{array}{c}\text { Ratio } \\
\mathrm{R}_{3}\end{array}$} \\
\hline$\overline{\mathrm{x}}$ & $\overline{\mathrm{Y}}$ & $\mathrm{N} / \mathrm{cm}^{2}$ & psi & $\mathrm{cm}$ & іп. & & $\mathrm{cm}$ & in. & \\
\hline \multirow[t]{16}{*}{$9 \overline{\mathrm{b}}$} & $9 \overline{\mathrm{a}}$ & $0.0252 \times 10^{6}$ & $0.0365 \times 10^{6}$ & $0.0401 \times 10^{-3}$ & $0.0158 \times 10^{-3}$ & 63.53 & $0.0409 \times 10^{-3}$ & $0.0161 \times 10^{-3}$ & 0.8600 \\
\hline & $11 \bar{a}$ & .0235 & .0341 & .0368 & .0145 & 9.039 & .0409 & .0161 & .9554 \\
\hline & $13 \bar{a}$ & .0197 & .0286 & .0300 & .0118 & 2.735 & .0409 & .0161 & 1.290 \\
\hline & $15 \overline{\mathrm{a}}$ & .0119 & .0173 & .0201 & .0079 & .9417 & .0411 & .0162 & 3.867 \\
\hline & $17 \bar{a}$ & 0 & 0 & .0107 & .0042 & .3032 & .0455 & .0179 & $---n$ \\
\hline & $19 \bar{a}$ & & & .0076 & .0030 & .1478 & .0599 & .0236 & $-\ldots$ \\
\hline & $21 \bar{a}$ & & & .0061 & .0024 & .0854 & .0790 & .0311 & ----- \\
\hline & $23 \overline{\mathrm{a}}$ & & & .0053 & .0021 & .0542 & .1021 & .0402 & $-\cdots-$ \\
\hline & $25 \overline{\mathrm{a}}$ & & & .0046 & .0018 & .0367 & .1288 & .0507 & ----- \\
\hline & $27 \bar{a}$ & & & .0041 & .0016 & .0260 & .1593 & .0627 & --.-- \\
\hline & $29 \overline{\mathrm{a}}$ & & & .0036 & .0014 & .0191 & .1930 & .0760 & - - \\
\hline & $31 \bar{a}$ & & & .0033 & .0013 & .0145 & .2306 & .0908 & ----- \\
\hline & $33 \overline{\mathrm{a}}$ & & & .0030 & .0012 & .0112 & .2715 & .1069 & $-\ldots$ \\
\hline & $35 \bar{a}$ & & & .0028 & .0011 & .0089 & .3160 & .1244 & -..-- \\
\hline & $37 \overline{\mathrm{a}}$ & & & .0025 & .0010 & .0071 & .3640 & .1433 & -.... \\
\hline & $39 \bar{a}$ & 1 & 1 & .0023 & .0009 & .0058 & .4153 & .1635 & $-\cdots$ \\
\hline $11 \bar{b}$ & $9 \overline{\mathrm{a}}$ & .0235 & .0341 & .0386 & .0152 & 17.06 & .0409 & .0161 & .9431 \\
\hline $13 \overline{\mathrm{b}}$ & & .0197 & .0286 & .0353 & .0139 & 6.410 & .0409 & .0161 & 1.161 \\
\hline $15 \bar{b}$ & & .0119 & .0173 & .0307 & .0121 & 2.948 & .0411 & .0162 & 1.855 \\
\hline $17 \bar{b}$ & & 0 & 0 & .0254 & .0100 & 1.501 & .0424 & .0167 & ----- \\
\hline $19 \overline{\mathrm{b}}$ & & & & .0221 & .0087 & .8849 & .0472 & .0186 & $\ldots$ \\
\hline $21 \bar{b}$ & & & & .0198 & .0078 & .5700 & .0546 & .0215 & $\ldots$ \\
\hline $23 \overrightarrow{\mathrm{b}}$ & & & & .0180 & .0071 & .3900 & .0643 & .0253 & -.-.- \\
\hline $25 \overline{\mathrm{b}}$ & & & & .0165 & .0065 & .2789 & .0759 & .0299 & ...... \\
\hline $27 \bar{b}$ & & & & .0152 & .0060 & .2065 & .0892 & .0351 & $\ldots$ \\
\hline $29 \bar{b}$ & & & - & .0142 & .0056 & .1572 & .1044 & .0411 & ----- \\
\hline $31 \bar{b}$ & & & & .0132 & .0052 & .1225 & .1214 & .0478 & $\ldots$ \\
\hline $33 \bar{b}$ & & & & .0124 & .0049 & .0973 & .1402 & .0552 & $\ldots$ \\
\hline $35 \overline{\mathrm{b}}$ & & & & .0117 & .0046 & .0785 & .1605 & .0632 & ----- \\
\hline $37 \bar{b}$ & & & & .0109 & .0043 & .0643 & .1829 & .0720 & $\ldots$ \\
\hline $39 \bar{b}$ & & 1 & 1 & .0104 & .0041 & .0533 & .2068 & .0814 & $\ldots$ \\
\hline
\end{tabular}


TABLE X. - CHARACTERISTICS OF FILM SHAPE ALONG SEMIMAJOR AND SEMIMINOR AXES WHEN

THESE AXES ARE DIVIDED INTO FIVE EQUAL DIVISIONS AND THE DIMENSIONLESS LOAD

PARAMETER IS $0.2102 \times 10^{-7}$; THAT IS, CONDITION 3 OF TABLE I, OR A

SPHERE IN CONTACT WITH AN OUTER-RACE GROOVE

[Ratio $\left.\mathrm{R}_{1}=\mathrm{S} / \overline{\mathrm{S}}, 1.000.\right]$

\begin{tabular}{|c|c|c|c|c|c|c|c|c|c|}
\hline \multicolumn{2}{|c|}{ Coordinates } & \multicolumn{2}{|c|}{ Pressure, $p$} & \multicolumn{2}{|c|}{ Elastic deformation, $w$} & \multirow{2}{*}{$\begin{array}{l}\text { Ratio } \\
R_{2}=\frac{w}{S}\end{array}$} & \multicolumn{2}{|c|}{ Total separation, $\mathrm{S}+\mathrm{w}$} & \multirow{2}{*}{$\begin{array}{c}\text { Ratio } \\
\mathrm{R}_{3}\end{array}$} \\
\hline$\overline{\mathrm{X}}$ & $\bar{Y}$ & $\mathrm{~N} / \mathrm{cm}^{2}$ & psi & $\mathrm{cm}$ & in. & & $\mathrm{cm}$ & in. & \\
\hline $11 \vec{b}$ & $11 \bar{a}$ & $0.0253 \times 10^{6}$ & $0.0367 \times 10^{6} \mid$ & $0.0401 \times 10^{-3}$ & $0.0158 \times 10^{-3}$ & 99.24 & $0.0406 \times 10^{-3}$ & $0.0160 \times 10^{-3}$ & 0.1962 \\
\hline & $13 \bar{a}$ & .0243 & .0352 & .0378 & .0149 & 14.58 & .0406 & .0160 & .1273 \\
\hline & $15 \bar{a}$ & .0220 & .0319 & .0335 & .0132 & 4. 786 & .0404 & .0159 & -.0682 \\
\hline & $17 \mathrm{a}$ & .0181 & .0262 & .0269 & .0106 & 1.981 & .0406 & .0160 & .0094 \\
\hline & $19 \bar{a}$ & .0108 & .0157 & .0185 & .0073 & .8242 & .0409 & .0161 & 1.621 \\
\hline & $21 \bar{a}$ & 0 & 0 & .0107 & .0042 & .3220 & .0442 & .0174 & $-\ldots$ \\
\hline & $23 \bar{a}$ & & & .0081 & .0032 & .1749 & .0546 & .0215 & $-\ldots$ \\
\hline & $25 \bar{a}$ & & & .0066 & .0026 & .1085 & .0686 & .0270 & $-\ldots$ \\
\hline & $27 \bar{a}$ & & & .0058 & .0023 & .0725 & .0853 & .0336 & $-\therefore-$ \\
\hline & $29 \bar{a}$ & & & .0051 & .0020 & .0510 & .1044 & .0411 & -..... \\
\hline & $31 \mathrm{a}$ & & . & .0046 & .0018 & .0373 & .1257 & .0495 & - $-\therefore--$ \\
\hline & $33 \bar{a}$ & & & .0041 & .0016 & .0282 & .1496 & .0589 & $\mid--\cdots$ \\
\hline & $35 \bar{a}$ & & & .0038 & .0015 & .0218 & .1755 & .0691 & $\ldots$ \\
\hline & $37 \bar{a}$ & : & & .0036 & .0014 & .0172 & .2040 & .0803 & $-\therefore-\ldots$ \\
\hline & $39 \bar{a}$ & : & & .0033 & .0013 & .0138 & .2344 & .0923 & -.... \\
\hline & $41 \bar{a}$ & & . & .0030 & .0012 & .0113 & .2672 & .1052 & $\ldots$ \\
\hline & $43 \bar{a}$ & & & .0028 & .0011 & .0093 & .3023 & .1190 & - \\
\hline & $45 \bar{a}$ & & & .0025 & .0010 & .0078 & .3393 & .1336 & -.... \\
\hline & $47 \bar{a}$ & & . & .0025 & .0010 & .0066 & .3787 & .1491 & $-\ldots$ \\
\hline & $49 \bar{a}$ & $\gamma$ & 1 & .0023 & .0009 & .0056 & .4204 & .1655 & $\ldots$ \\
\hline $13 \overline{\mathrm{b}}$ & $11 \mathrm{a}$ & .0243 & .0352 & .0391 & .0154 & 27.05 & .0406 & .0160 & .2210 \\
\hline $15 \overline{\mathrm{b}}$ & . & .0220 & .0319 & .0371 & .0146 & 10.50 & .0406 & .0160 & .2814 \\
\hline $17 \bar{b}$ & & .0181 & .0262 & .0340 & .0134 & 5.105 & .0406 & .0160 & .4123 \\
\hline $19 \bar{b}$ & & .0108 & .0157 & .0300 & .0118 & 2.767 & .0409 & .0161 & .8459 \\
\hline $21 \bar{b}$ & & 0 & 0 & .0257 & .0101 & 1.597 & .0417 & .0164 & $-\cdots$ \\
\hline $23 \overline{\mathrm{b}}$ & & & & .0229 & .0090 & 1. 025 & .0452 & .0178 & -.... \\
\hline $25 \overline{\mathrm{b}}$ & & & & .0208 & .0082 & .7020 & .0503 & .0198 & $-\cdots$ \\
\hline $27 \bar{b}$ & & & & .0191 & .0075 & .5036 & .0572 & .0225 & - \\
\hline $29 \bar{b}$ & & & & .0178 & .0070 & .3742 & .0650 & .0256 & $-\cdots$ \\
\hline $31 \bar{b}$ & & & & .0165 & .0065 & .2859 & .0744 & .0293 & $\mid \cdots$ \\
\hline $33 \overline{\mathrm{b}}$ & & & & .0155 & .0061 & .2235 & .0848 & .0334 & $-\cdots$ \\
\hline $35 \overline{\mathrm{b}}$ & & & & .0145 & .0057 & .1781 & .0963 & .0379 & $--\ldots$ \\
\hline $37 \overline{\mathrm{b}}$ & & & & .0137 & .0054 & .1442 & .1090 & .0429 & $\ldots$ \\
\hline $39 \overline{\mathrm{b}}$ & & & & .0130 & .0051 & .1184 & .1229 & .0484 & $\ldots$ \\
\hline $41 \overrightarrow{\mathrm{b}}$ & & & & .0124 & .0049 & .0984 & .1379 & .0543 & $\ldots$ \\
\hline $43 \bar{b}$ & & & & .0117 & .0046 & .0827 & .1539 & .0606 & $\ldots$ \\
\hline $45 \vec{b}$ & & & & .0112 & .0044 & .0702 & .1712 & .0674 & $-\cdots$ \\
\hline $47 \vec{b}$ & & & & .0107 & .0042 & .0600 & .1895 & .0746 & -..... \\
\hline $49 \overline{\mathrm{b}}$ & & 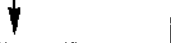 & 1 & .0102 & .0040 & .0517 & .2088 & .0822 & $-\ldots$. \\
\hline
\end{tabular}


TABLE XI. - CHARACTERISTICS OF FILM SHAPE ALONG SEMIMAJOR AND SEMIMINOR AXES WHEN THESE AXES ARE DIVIDED INTO THREE EQUAL DIVISIONS AND THE DIMENSIONLESS LOAD PARAMETER IS $0.2102 \times 10^{-5}$; THAT IS, CONDITION 4 OF TABLE I, OR A SPHERE IN CONTACT WITH AN OUTER-RACE GROOVE

\begin{tabular}{|c|c|c|c|c|c|c|c|c|c|c|}
\hline \multicolumn{2}{|c|}{ Coordinates } & \multicolumn{2}{|c|}{ Pressure, $p$} & \multirow{2}{*}{$\begin{array}{c}\text { Ratio } \\
\mathbf{R}_{1}=\frac{\mathrm{S}}{\bar{S}}\end{array}$} & \multicolumn{2}{|c|}{ Elastic deformation, $w$} & \multirow{2}{*}{$\begin{array}{c}\text { Ratio } \\
\mathrm{R}_{2}=\frac{\mathrm{w}}{\mathrm{S}}\end{array}$} & \multicolumn{2}{|c|}{ Total separation, $\mathrm{S}+\mathrm{w}$} & \multirow{2}{*}{$\begin{array}{l}\text { Ratio } \\
\mathrm{R}_{3}\end{array}$} \\
\hline $\bar{x}$ & $\overrightarrow{\mathrm{Y}}$ & $\mathrm{N} / \mathrm{cm}^{2}$ & psi & & $\mathrm{cm}$ & in. & & $\mathrm{cm}$ & in. & \\
\hline \multirow[t]{12}{*}{$7 \vec{b}$} & $7 \mathrm{a}^{-}$ & $0.1153 \times 10^{6}$ & $0.1673 \times 10^{6}$ & 1.000 & $0.8588 \times 10^{-3}$ & $0.3381 \times 10^{-3}$ & 35.42 & $0.8829 \times 10^{-3}$ & $0.3476 \times 10^{-3}$ & 1.028 \\
\hline & $9 \bar{a}$ & .1009 & .1463 & & .7262 & .2859 & 4.662 & .8821 & .3473 & 1. 135 \\
\hline & $11 \bar{a}$ & .0625 & .0907 & & .4745 & .1868 & 1.132 & .8933 & .3517 & 4.033 \\
\hline & $13 \bar{a}$ & 0 & 0 & & .2202 & .0867 & .2705 & 1.034 & .4069 & 7. 494 \\
\hline & $15 \bar{a}$ & & & & .1511 & .0595 & .1128 & 1. 491 & .5869 & 4.994 \\
\hline & $17 a$ & & & .9999 & .1181 & .0465 & .0591 & 2.116 & .8329 & 4.353 \\
\hline & $19 \overline{\mathrm{a}}$ & & & .9999 & .0978 & .0385 & .0351 & 2.885 & 1.136 & ---- \\
\hline & $21 \bar{a}$ & & & .9999 & .0836 & .0329 & .0225 & 3.792 & 1. 493 & $\ldots$ \\
\hline & $23 \bar{a}$ & & & .9998 & .0732 & .0288 & .0154 & 4.834 & 1.903 & $-\cdots-$ \\
\hline & $25 \bar{a}$ & & & .9998 & .0650 & .0256 & .0109 & 6.010 & 2.366 & ---- \\
\hline & $27 a$ & & & .9998 & .0587 & .0231 & .0081 & 7.318 & 2.881 & $-\cdots$ \\
\hline & $29 \overline{\mathrm{a}}$ & $\varphi$ & & .9997 & .0533 & $=0210$ & .0061 & 8.760 & 3.449 & $\ldots$ \\
\hline $9 \bar{b}$ & $7 \vec{a}$ & .1009 & .1463 & 1.000 & .7978 & .3141 & 9.205 & .8844 & .3482 & 1.267 \\
\hline $11 \bar{b}$ & & .0625 & .0907 & .9999 & .6789 & .2673 & 3.210 & .8905 & .3506 & 2.280 \\
\hline $13 \bar{b}$ & & 0 & 0 & .9999 & .5344 & .2104 & 1.340 & .9332 & .3674 & 2.820 \\
\hline $15 \overline{\mathrm{b}}$ & & 1 & & .9998 & .4519 & .1779 & .6966 & 1.100 & .4332 & 2.543 \\
\hline $17 \bar{b}$ & & & & .9996 & .3952 & .1556 & .4114 & 1.356 & .5338 & 2.517 \\
\hline $19 \bar{b}$ & & & & .9995 & .3523 & .1387 & .2638 & 1.687 & .6643 & $\ldots$ \\
\hline $21 \overline{\mathrm{b}}$ & & & & .9993 & .3180 & .1252 & .1794 & 2.090 & .8229 & $\cdots$ \\
\hline $23 \overline{\mathrm{b}}$ & & & & .9991 & .2898 & .1141 & .1276 & 2.560 & 1.008 & $-\cdots$ \\
\hline $25 \overline{\mathrm{b}}$ & & & & .9989 & .2662 & .1048 & .0940 & 3.099 & 1.220 & -... \\
\hline $27 \bar{b}$ & & & & .9987 & .2461 & .0969 & .0712 & 3.703 & 1.458 & $-\cdots$ \\
\hline $29 \bar{b}$ & & 1 & 1 & .9984 & .2289 & .0901 & .0552 & 4. 374 & 1.722 & $\cdots$ \\
\hline
\end{tabular}


TABLE XII. - CHARACTERISTICS OF FILM SHAPE A LONG SEMIMAJOR AND SEMIMINOR AXES WHEN THESE AXES ARE DIVIDED INTO FOUR EQUAL DIVISIONS AND THE DIMENSIONLESS LOAD PARAMETER IS $0.2102 \times 10^{-5}$; THAT IS, CONDITION 4 OF TABLE I, OR A SPHERE IN CONTACT WITH AN OUTER-RACE GROOVE

\begin{tabular}{|c|c|c|c|c|c|c|c|c|c|c|}
\hline \multicolumn{2}{|c|}{ Coordinates } & \multicolumn{2}{|c|}{ Pressure, p } & \multirow{2}{*}{$\begin{array}{c}\text { Ratio } \\
\mathrm{R}_{1}=\frac{\mathrm{S}}{\overline{\mathrm{S}}}\end{array}$} & \multicolumn{2}{|c|}{ Elastic deformation, $\dot{w}$} & \multirow{2}{*}{$\begin{array}{l}\text { Ratio } \\
\mathrm{R}_{2}=\frac{\mathrm{w}}{\mathrm{S}}\end{array}$} & \multicolumn{2}{|c|}{ Total separation, $\mathrm{S}+\mathrm{w}$} & \multirow{2}{*}{$\begin{array}{c}\text { Ratio } \\
\mathrm{R}_{3}\end{array}$} \\
\hline $\overrightarrow{\mathrm{x}}$ & $\overline{\mathrm{Y}}$ & $\mathrm{N} / \mathrm{cm}^{2}$ & psi & & $\mathrm{cm}$ & in. & & $\mathrm{cm}$ & in. & \\
\hline \multirow[t]{16}{*}{$9 \bar{b}$} & $9 \overline{\mathbf{a}}$ & $0.1168 \times 10^{6}$ & $0.1694 \times 10^{6}$ & 1.000 & $0.8664 \times 10^{-3}$ & $0.3411 \times 10^{-3}$ & 63.53 & $0.8801 \times 10^{-3}$ & $0.3465 \times 10^{-3}$ & 0.8604 \\
\hline & $11 \bar{a}$ & .1090 & .1581 & & .7922 & .3119 & 9.039 & .8799 & .3464 & 9549 \\
\hline & $13 \bar{a}$ & .0914 & .1326 & & .6444 & .2537 & 2.735 & .8801 & .3465 & 1.290 \\
\hline & $15 \bar{a}$ & .0555 & .0805 & & .4310 & .1697 & .9417 & .8849 & .3498 & 3.869 \\
\hline & $17 \bar{a}$ & 0 & 0 & & .2286 & .0900 & .3032 & .9822 & .3867 & \\
\hline & $19 \bar{a}$ & & & & .1661 & .0654 & .1478 & 1.290 & .5077 & \\
\hline & $21 \bar{a}$ & & & 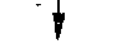 & .1339 & .0527 & .0854 & 1.702 & .6699 & \\
\hline & $23 \bar{a}$ & & & .9999 & .1130 & .0445 & .0542 & 2.199 & .8657 & \\
\hline & $25 \bar{a}$ & & & & .0983 & .0387 & .0367 & 2.776 & 1. 093 & \\
\hline & $27 \bar{a}$ & & & & .0869 & .0342 & .0260 & 3.432 & 1. 351 & \\
\hline & $29 \bar{a}$ & & & $\downarrow$ & .0780 & .0307 & .0191 & 4.161 . & 1.638 & \\
\hline & $31 \bar{a}$ & & r & .9998 & .0709 & .0279 & .0145 & 4.968 & 1.956 & \\
\hline & $33 \bar{a}$ & & & .9998 & .0650 & .0256 & .0112 & 5.850 & 2.303 & \\
\hline & $35 \bar{a}$ & & . & .9998 & .0599 & .0236 & .0089 & 6.807 & 2.680 & - \\
\hline & $37 \mathrm{a}$ & & & .9997 & .0556 & .0219 & .0071 & 7.838 & 3.086 & \\
\hline & $39 \bar{a}$ & 1 & & .9997 & .0518 & .0204 & .0058 & 8.946 & 3.522 & - \\
\hline $11 \bar{b}$ & $9 \overline{\mathbf{a}}$ & .1090 & .1581 & 1. 000 & .8319 & .3275 & 17.06 & .8806 & .3467 & .9433 \\
\hline $13 \bar{b}$ & & .0914 & .1326 & 1.000 & .7628 & .3003 & 6.410 & .8816 & .3471 & 1.162 \\
\hline $15 \overline{\mathrm{b}}$ & & .0555 & .0805 & .9999 & .6612 & .2603 & 2.948 & .8854 & .3486 & 1.855 \\
\hline $17 \bar{b}$ & & 0 & 0 & .9999 & .5476 & .2156 & 1.501 & .9124 & .3592 &,----- \\
\hline $19 \overrightarrow{\mathrm{b}}$ & & & 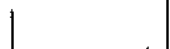 & .9998 & .4780 & .1882 & .8849 & 1.019 & .4010 & \\
\hline $21 \bar{b}$ & & & & .9997 & .4280 & .1685 & .5700 & 1.179 & .4642 & \\
\hline $23 \bar{b}$ & & & & .9996 & .3886 & .1530 & .3899 & 1.386 & .5455 & - \\
\hline $25 \bar{b}$ & & & & .9995 & .3564 & .1403 & .2789 & 1.634 & .6433 & $--\div--$ \\
\hline $27 \bar{b}$ & & & & .9994 & .3292 & .1296 & 2065 & 1.923 & .7570 & $\therefore$ \\
\hline $29 \overrightarrow{\mathrm{b}}$ & & & & .9993 & .3058 & .1204 & .1572 & 2.251 & .8861 & --1. \\
\hline $31 \bar{b}$ & & & & .9991 & .28555 & .1124 & .1225 & 2.616 & 1.030 & ---- \\
\hline $33 \overline{\mathrm{b}}$ & & & & .9989 & .2677 & .1054 & .0973 & 3.020 & 1.189 & $\cdots$ \\
\hline $35 \bar{b}$ & & & & .9988 & .2520 & .0992 & .0785 & 3.462 & 1. 363 & $\therefore---$ \\
\hline $37 \bar{b}$ & & & & .9986 & .2380 & 0937 & .0631 & 3.940 & 1.551 & $-\cdots$ \\
\hline $39 \overline{\mathbf{b}}$ & & & 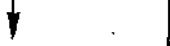 & .9984 & .2253 & .0887 & .0533 & 4.453 & 1.753 & 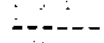 \\
\hline
\end{tabular}


TABLE XIII. - CHARACTERISTICS OF FILM SHAPE ALONG SEMIMAJOR AND SEMIMINOR AXES WHEN THESE AXES ARE DIVIDED INTO FIVE EQUAL DIVISIONS AND THE DIMENSIONLESS LOAD PARAMETER IS $0.2102 \times 10^{-5}$;

THAT IS, CONDITION 4 OF TABLE I, OR A SPHERE IN CONTACT WITH AN OUTER-RACE GROOVE

\begin{tabular}{|c|c|c|c|c|c|c|c|c|c|c|}
\hline \multicolumn{2}{|c|}{ Coordinates } & \multicolumn{2}{|c|}{ Pressure, $p$} & \multirow{2}{*}{$\mathrm{R}_{1}=\frac{\mathrm{S}}{\overline{\mathrm{S}}}$} & \multicolumn{2}{|c|}{ Elastic deformation, w } & \multirow{2}{*}{$\begin{array}{l}\text { Ratio } \\
R_{2}=\frac{w}{S}\end{array}$} & \multicolumn{2}{|c|}{ Total separation, $S+w$} & \multirow{2}{*}{$\begin{array}{c}\text { Ratio } \\
R_{3}\end{array}$} \\
\hline $\bar{x}$ & $\overline{\mathrm{Y}}$ & $\mathrm{N} / \mathrm{cm}^{2}$ & psi & & $\mathrm{cm}$ & in. & & $\mathrm{cm}$ & in. & \\
\hline $11 \vec{b}$ & $11 \bar{a}$ & $0.1179 \times 10^{6}$ & $0.1704 \times 10^{6}$ & 1.000 & $0.8661 \times 10^{-3}$ & $0.3410 \times 10^{-3}$ & 99.24 & $0.8750 \times 10^{-3}$ & $0.3445 \times 10^{-3}$ & 0.1998 \\
\hline & $13 \bar{a}$ & .1126 & .1633 & & .8179 & .3220 & 14.58 & .8740 & .3441 & .1244 \\
\hline & $15 \bar{a}$ & .1021 & .1481 & & .7216 & .2841 & 4.786 & .8725 & .3435 & -.0668 \\
\hline & $17 \bar{a}$ & .0839 & .1217 & & .5804 & .2285 & 1.981 & .8733 & .3438 & .0088 \\
\hline & $19 \bar{a}$ & .0503 & .0730 & & .3975 & .1565 & .8242 & .8799 & .3464 & 1.617 \\
\hline & $21 \bar{a}$ & 0 & 0 & & .2316 & .0912 & .3220 & .9507 & .3743 & $-\cdots--$ \\
\hline & $23 \bar{a}$ & & & & .1755 & .0691 & .1749 & 1.179 & .4640 & ----- \\
\hline & $25 \bar{a}$ & & & $\downarrow$ & .1448 & .0570 & .1085 & 1. 480 & .5825 & 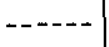 \\
\hline & $27 \bar{a}$ & & & .9999 & .1242 & .0489 & .0725 & 1.838 & .7236 & ----- \\
\hline & $29 \bar{a}$ & & & & .1092 & .0430 & .0510 & 2.249 & .8855 & ----- \\
\hline & $31 \bar{a}$ & & & & .0975 & .0384 & .0373 & 2.710 & 1.067 & $\ldots--$ \\
\hline & $33 \bar{a}$ & & & & .0884 & .0348 & .0282 & 3.223 & 1. 269 & $\ldots \ldots$ \\
\hline & $35 \overline{\mathfrak{a}}$ & & & & .0808 & .0318 & .0210 ia & 3.785 & 1.490 & -.-- \\
\hline & $37 \mathrm{a}$ & & & 1 & .0744 & .0293 & .0172 & 4.392 & 1.729 & $\ldots$ \\
\hline & $39 \overline{\mathrm{a}}$ & & & .9998 & .0688 & .0271 & .0138 & 5.050 & 1.988 & -...- \\
\hline & $41 \bar{a}$ & & & & .0643 & .0253 & .0113 & 5.756 & 2.266 & 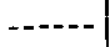 \\
\hline & $43 \bar{a}$ & & & & .0602 & .0237 & .0093 & 6.510 & 2.563 & $-\ldots$ \\
\hline & $45 \bar{a}$ & & & 1 & .0566 & .0223 & .0078 & 7.310 & 2.878 & $\ldots$ \\
\hline & $47 \bar{a}$ & & & .9997 & .0536 & .0211 & .0066 & 8.161 & 3.213 & $-\cdots--$ \\
\hline & $49 \overline{\mathrm{a}}$ & 1 & $\uparrow$ & .9997 & .0508 & .0200 & .0056 & 9.058 & 3.566 & $\ldots \ldots$ \\
\hline $13 \overline{\mathbf{b}}$ & $11 \bar{a}$ & .1126 & .1633 & 1.000 & .8440 & .3323 & 27.05 & .8753 & .3446 & .2262 \\
\hline $15 \bar{b}$ & & .1021 & .1481 & 1.000 & .7996 & .3148 & 10.50 & .8755 & .3447 & .2836 \\
\hline $17 \overline{\mathrm{b}}$ & & .0839 & .1217 & 1.000 & .7330 & .2886 & 5.105 & .8766 & .3451 & .4141 \\
\hline $19 \bar{b}$ & & .0503 & .0730 & .9999 & .6459 & .2543 & 2.767 & .8793 & .3462 & .8447 \\
\hline $21 \bar{b}$ & & 0 & 0 & .9999 & .5525 & .2175 & 1.597 & .8981 & .3536 & $-\ldots .$. \\
\hline $23 \overline{\mathrm{b}}$ & & & & .9998 & .4925 & .1939 & 1.025 & .9731 & .3831 & $-\ldots$ \\
\hline $25 \overline{\mathrm{b}}$ & & & & .9998 & .4478 & .1763 & .7020 & 1.086 & .4275 & $\cdots$ \\
\hline $27 \overline{\mathrm{b}}$ & & & & .9997 & .4117 & .1621 & .5036 & 1.230 & .4841 & $-\cdots$ \\
\hline $29 \overline{\mathrm{b}}$ & & & & .9996 & .3818 & .1503 & .3742 & 1. 402 & .5519 & $\ldots$ \\
\hline $31 \overline{\mathbf{b}}$ & & & & .9995 & .3559 & .1401 & .2859 & 1.601 & .6302 & $-\cdots$ \\
\hline $33 \overline{\mathrm{b}}$ & & & & .9994 & .3335 & 1313 & .2235 & 1.825 & .7187 & $-\ldots$ \\
\hline $35 \vec{b}$ & & & & .9993 & .3137 & .1235 & .1781 & 2.075 & .8171 & $-\cdots$ \\
\hline $3 \bar{b}$ & & & & .9992 & .2962 & .1166 & .1442 & 2. 350 & .9252 & $\ldots$ \\
\hline $39 \overline{\mathrm{b}}$ & & & & .9991 & .2804 & .1104 & .1184 & 2.649 & 1.043 & $-\ldots$ \\
\hline $41 \bar{b}$ & & & & .9990 & .2664 & .1049 & .0984 & 2.972 & 1.170 & ---- \\
\hline $43 \bar{b}$ & & & & .9988 & .2535 & .0998 & .0827 & 3.320 & 1.307 & $\ldots$ \\
\hline $45 \bar{b}$ & & & & .9987 & .2418 & .0952 & .0702 & 3.688 & 1. 452 & ---.-- \\
\hline $47 \overline{\mathrm{b}}$ & & & & .9985 & .2311 & .0910 & .0600 & 4.082 & 1. 607 & $\ldots$ \\
\hline $49 \overline{\mathrm{b}}$ & & 1 & 1 & .9983 & .2212 & .0871 & .0517 & 4.501 & 1.772 & 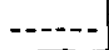 \\
\hline
\end{tabular}




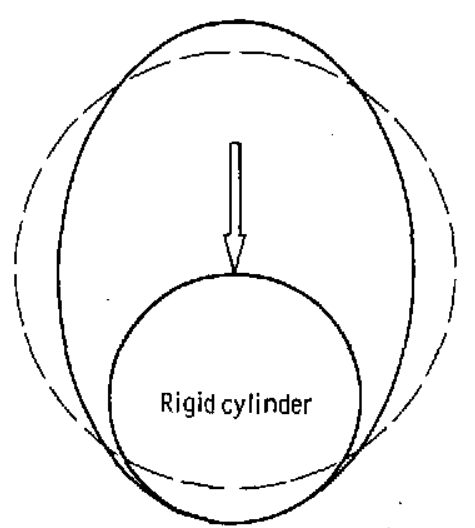

(a) Distortion of the element.

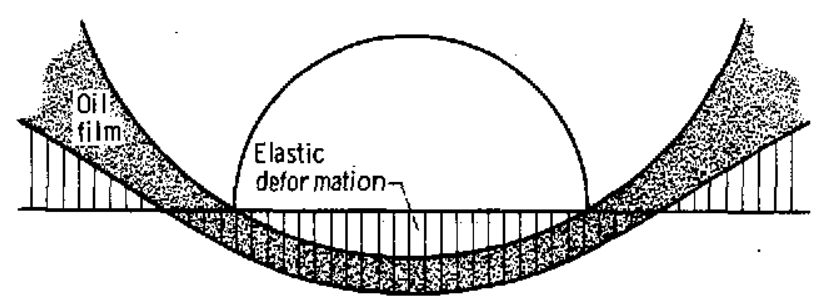

(b) Local elastic defor mation.

Figure 1. - Types of elastic deformation.

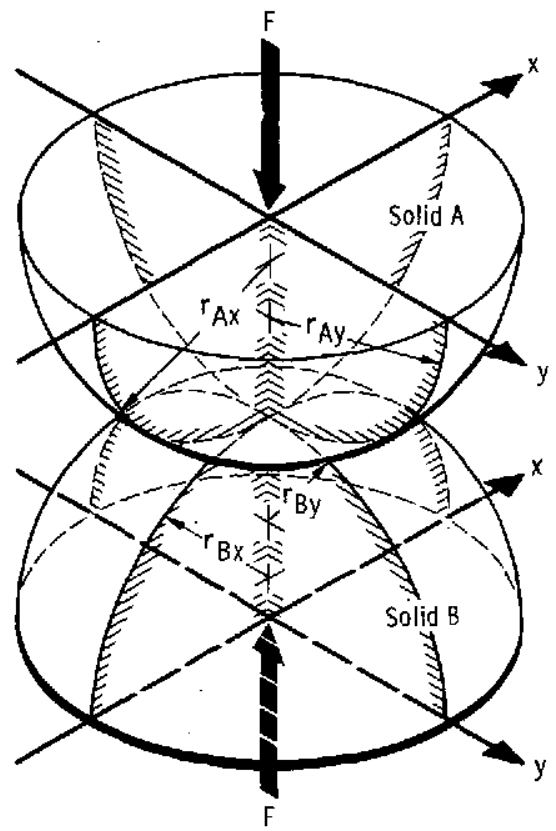

Figure 2 - Geometry of contacting elastic solids. 

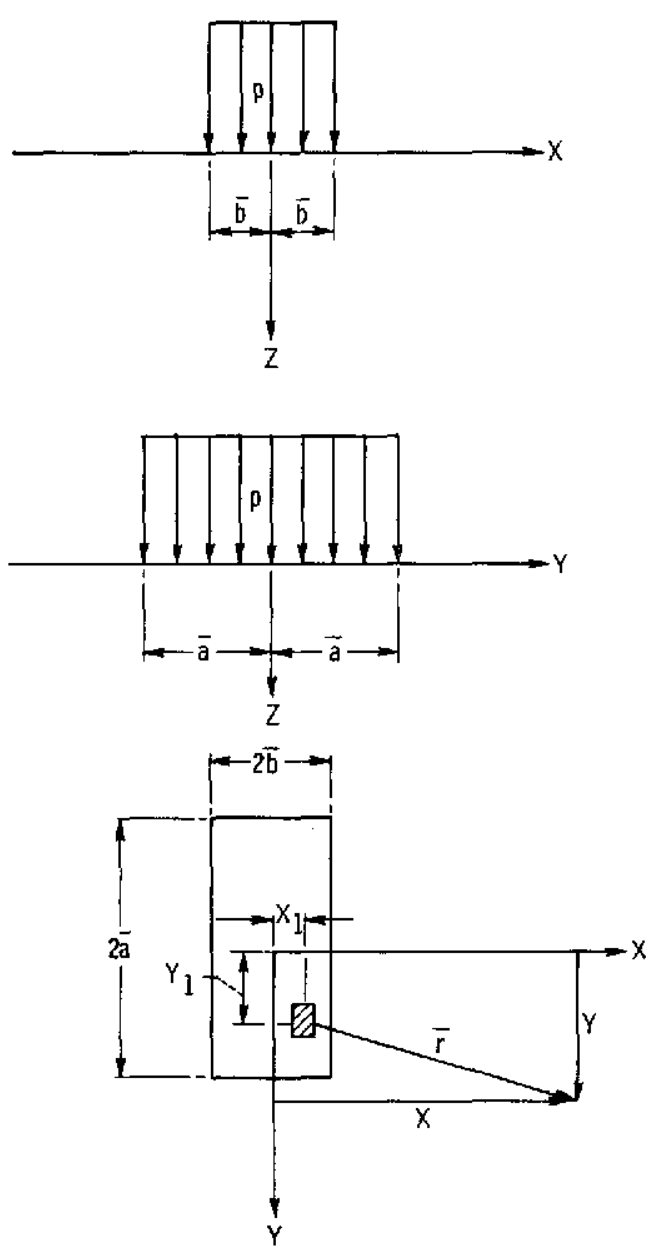

Figure 3. - Surface deformation of a semi-infinite body subjected to a uniform pressure over a rectangular area.

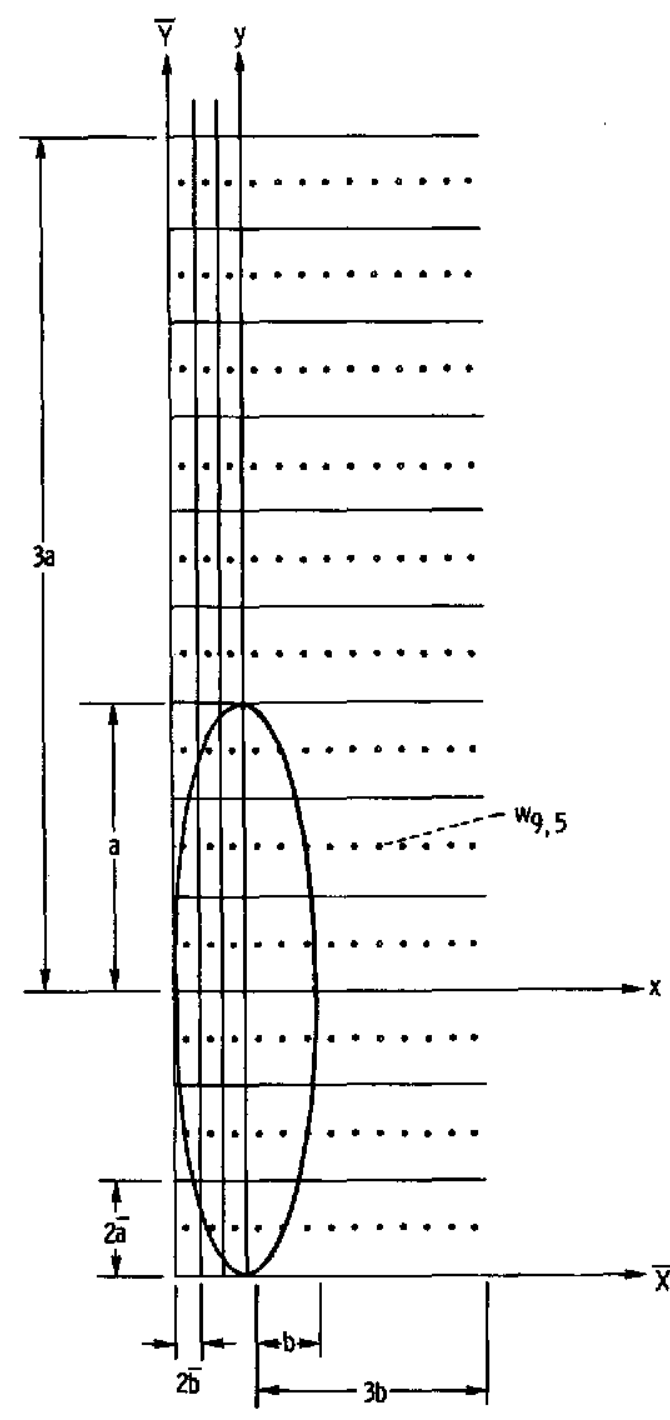

Figure 4. - Example division of area in and around contact zone into equal rectangular areas. 


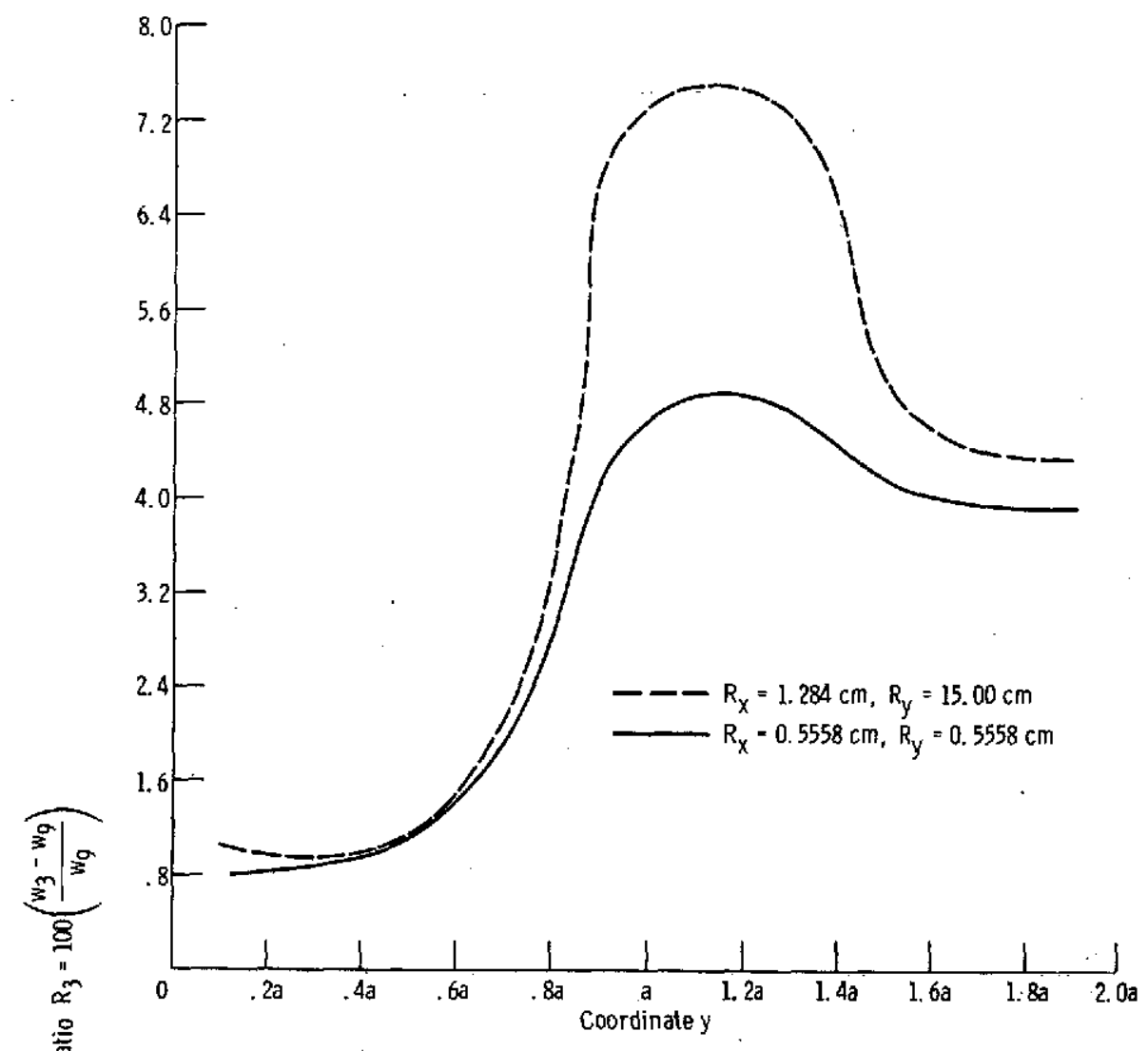

(a) Semimajor axis.

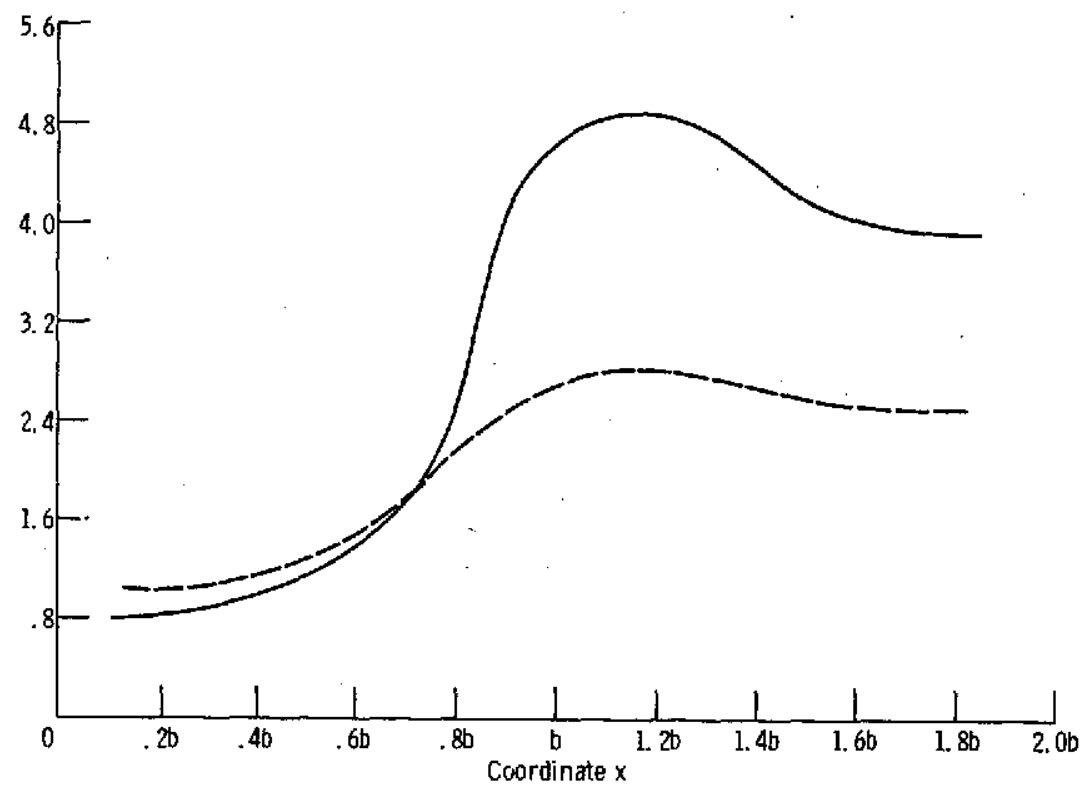

(b) Semiminor axis.

Figure 5. - Effect of lacation along semimajor and semiminor axes on percentage difference in elastic deformation when $m=3$ and 9 . 


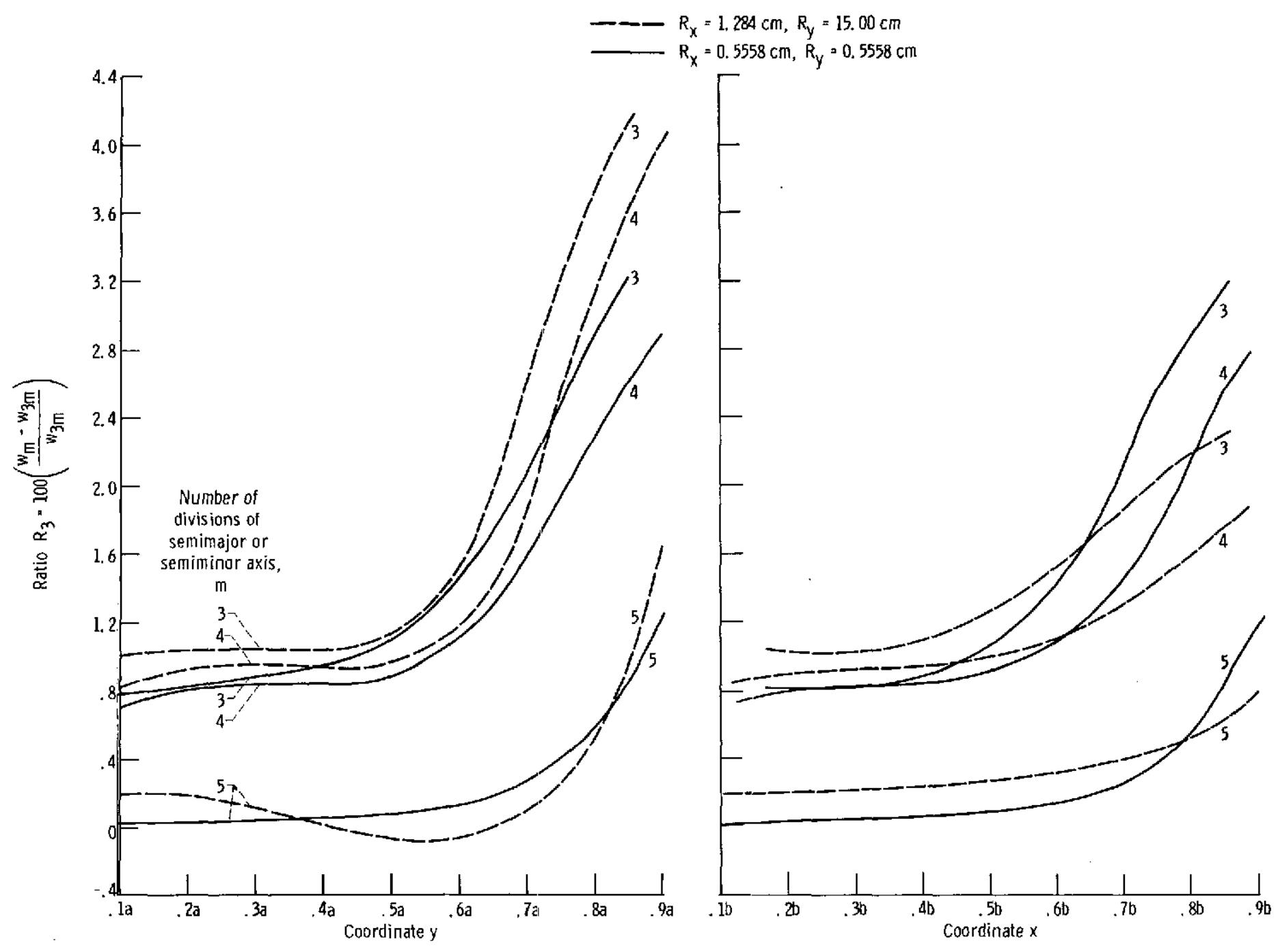

(a) Semimajor axis.

(b) Semiminor axis.

Figure 6. - Effect of location along semimajor and semiminor axes on percentage difference in elastic deformation when $\mathrm{m}=3,4$, and 5 and on the more exact film shape when $m=9,12$, and 15 , respectively. 


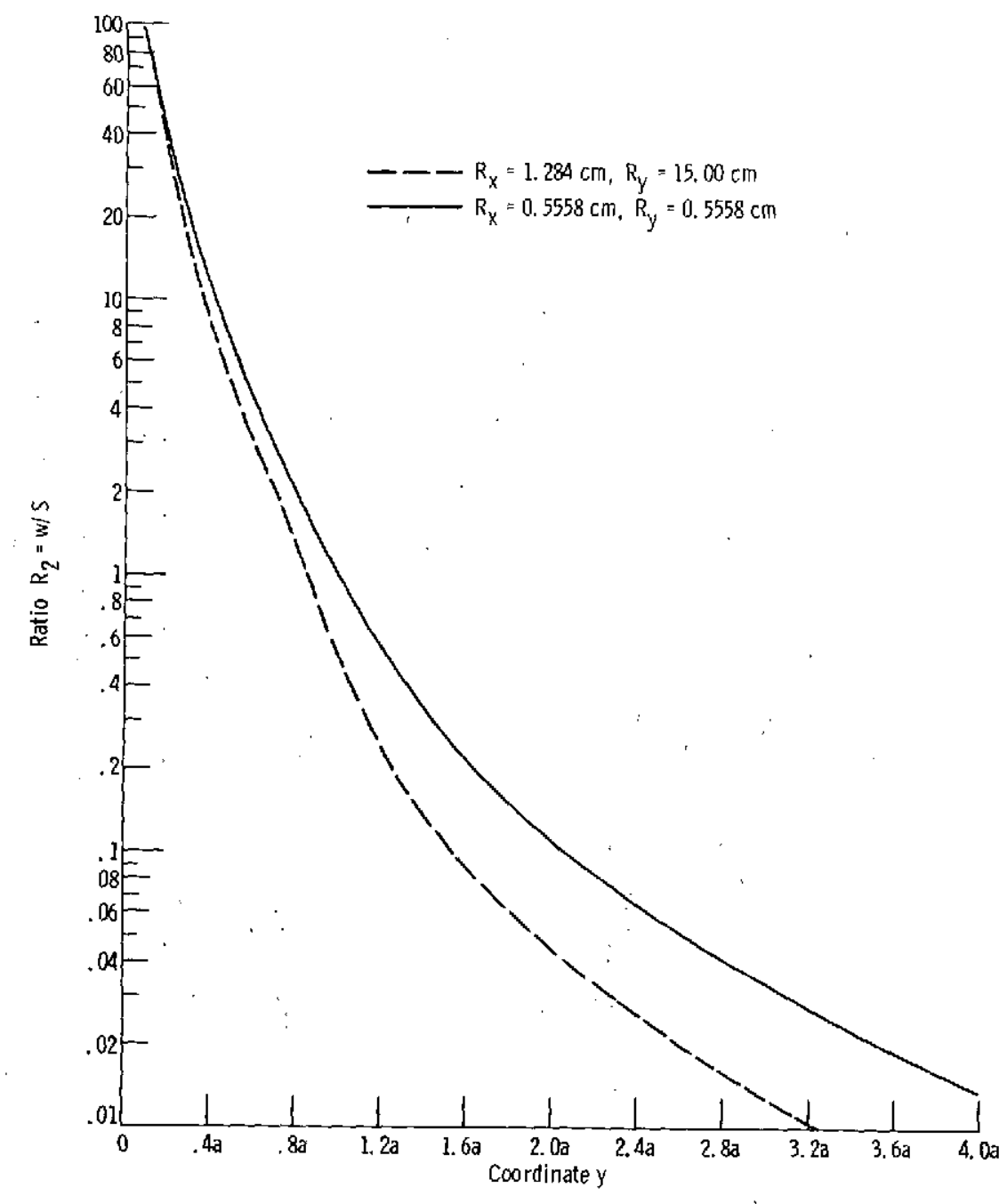

(a) Semimajor axis.

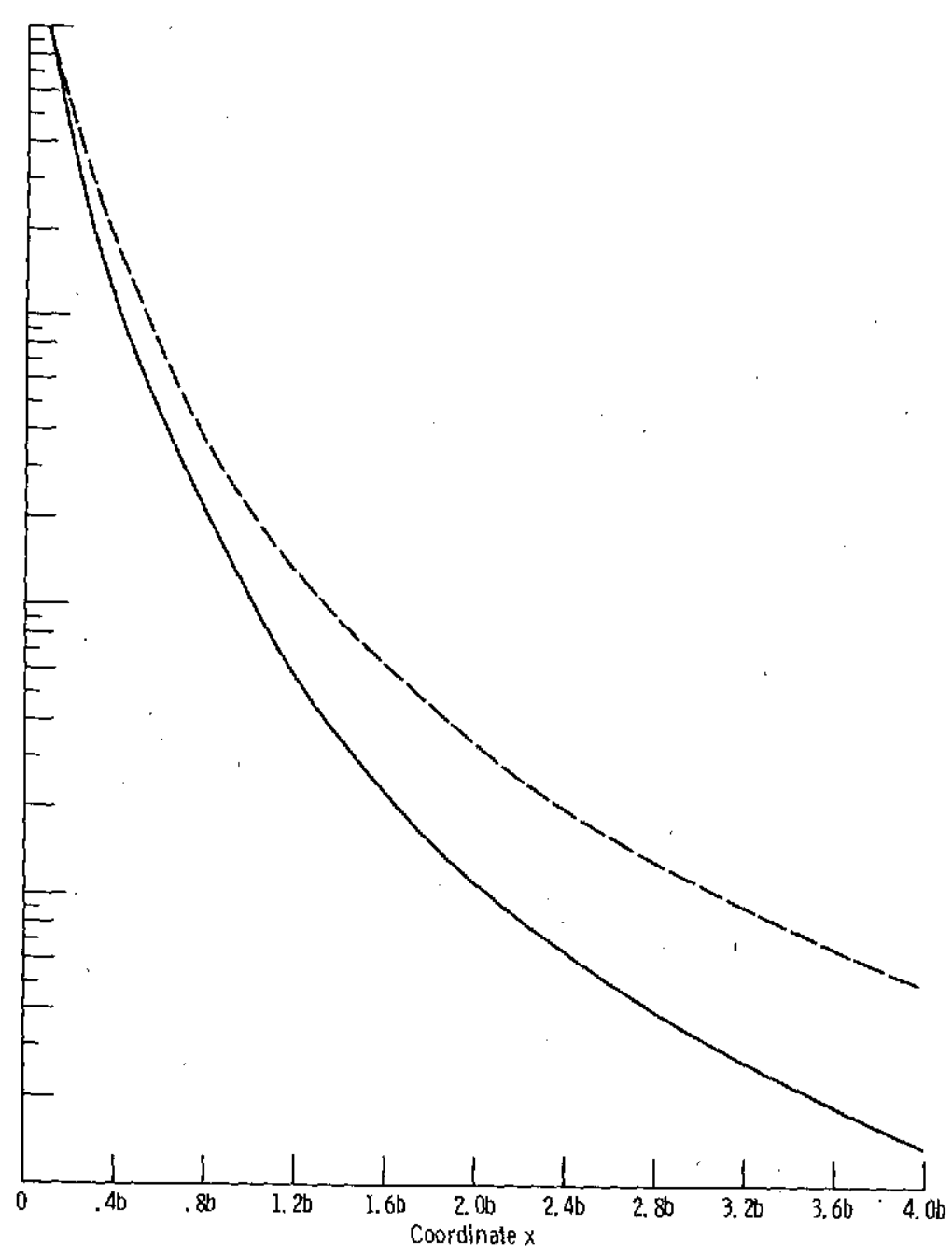

(b) Semiminor axis,

Figure 7. - Effect of location along semimajor and semiminor axes on ratio of elastic deformation to distance separating two solids in contact due to geometry of the solids. 


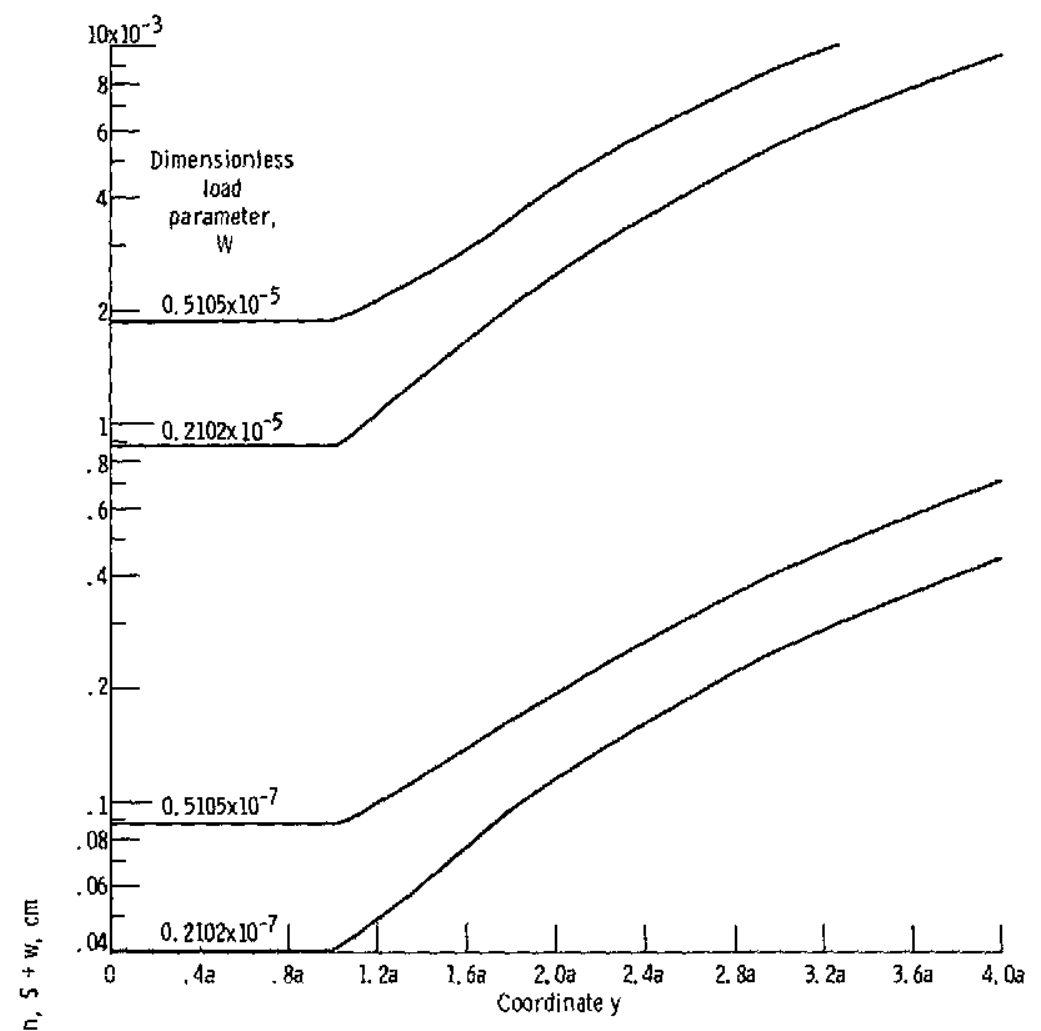

(a) Semimajor axis.

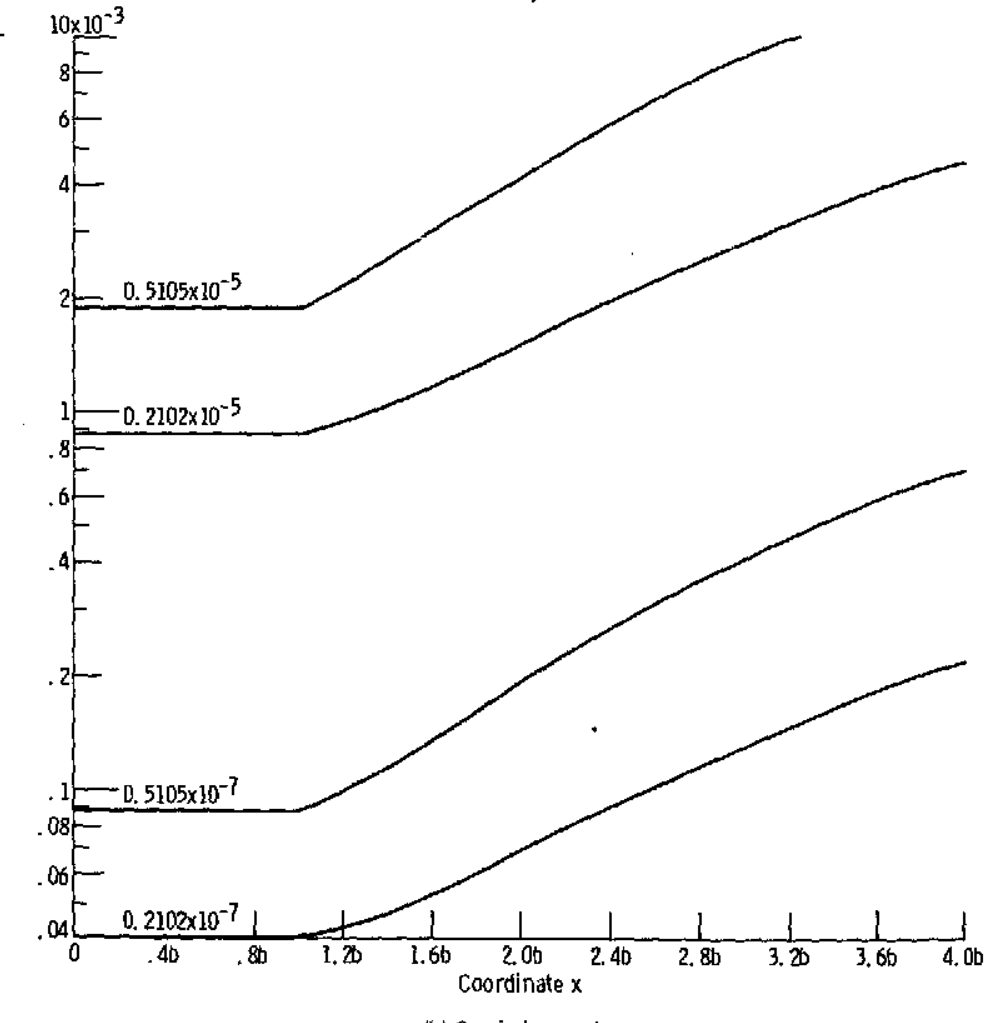

(b) Semiminar axis.

Figure 8. - Effect of location along semimajor and semiminor axes on separation due to geometry of contacting solids plus elastic deformation. 


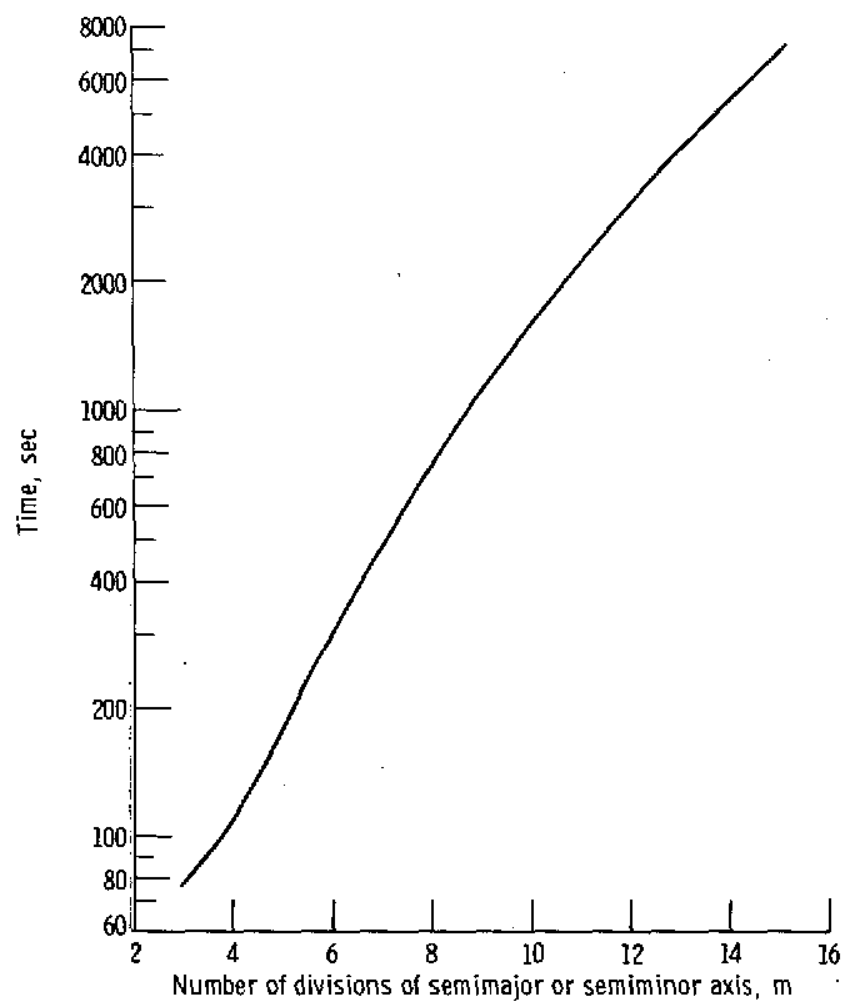

Figure 9. - Effect of number of divisions across ellipse axis on computer run time. 